Article

\title{
Tipping Growth Inhibition into Apoptosis by Combining Treatment with MDM2 and WIP1 Inhibitors in p53 ${ }^{\mathrm{WT}}$ Uterine Leiomyosarcoma
}

\author{
Victoria Chamberlain ${ }^{1}$, Yvette Drew ${ }^{1,2}$ and John Lunec ${ }^{1, *(D)}$ \\ 1 Newcastle University Centre for Cancer, Newcastle University, Newcastle upon Tyne NE2 4HH, UK; \\ v.m.chamberlain2@ncl.ac.uk (V.C.); yvette.drew@bccancer.bc.ca (Y.D.) \\ 2 BC Cancer Centre Vancouver and Faculty of Medicine, University of British Columbia, \\ Vancouver, BC V5Z 4EH, Canada \\ * Correspondence: john.lunec@newcastle.ac.uk
}

check for

updates

Citation: Chamberlain, V.; Drew, Y.; Lunec, J. Tipping Growth Inhibition into Apoptosis by Combining Treatment with MDM2 and WIP1 Inhibitors in $\mathrm{p} 53^{\mathrm{WT}}$ Uterine

Leiomyosarcoma. Cancers 2022, 14, 14 https://doi.org/10.3390/

cancers14010014

Academic Editors: Alberto Inga and Patricia A.J. Muller

Received: 31 October 2021

Accepted: 16 December 2021

Published: 21 December 2021

Publisher's Note: MDPI stays neutral with regard to jurisdictional claims in published maps and institutional affiliations.

Copyright: (c) 2021 by the authors. Licensee MDPI, Basel, Switzerland. This article is an open access article distributed under the terms and conditions of the Creative Commons Attribution (CC BY) license (https:// creativecommons.org/licenses/by/ $4.0 /)$.
Simple Summary: Uterine Leiomyosarcoma (uLMS) is a rare (0.8 per 100,000 women), aggressive cancer that predominantly affects post-menopausal women. Prognosis for these women is poor, with relapse following primary treatment occurring in up to $70 \%$ of cases. For women with recurrent or advanced uLMS, there is no optimal therapeutic strategy, and research to develop novel, targeted therapies is needed. This study investigates novel combinations in uLMS preclinical models. We present encouraging results using MDM2 inhibitor-based combination treatments, including the WIP1 phosphatase inhibitor GSK2830371. These data suggest that women with uLMS could respond to such combination treatments; therefore, these should be investigated in clinical trials. As these agents do not bind to and interfere with DNA, they offer a non-genotoxic alternative to the cytotoxic chemotherapy currently used in the recurrent setting.

Abstract: As there is no optimal therapeutic strategy defined for women with advanced or recurrent uLMS, there is an urgent need for the discovery of novel, targeted approaches. One such area of interest is the pharmacological inhibition of the MDM2-p53 interaction with small-molecularweight MDM2 inhibitors. Growth inhibition and cytotoxic assays were used to evaluate uLMS cell line responses to MDM2 inhibitors as single agents and in combination, qRT-PCR to assess transcriptional changes and Caspase-Glo 3/7 assay to detect apoptosis. RG7388 and HDM201 are potent, selective antagonists of the MDM2-p53 interaction that can effectively stabilise and activate p53 in a dose-dependent manner. GSK2830371, a potent and selective WIP1 phosphatase inhibitor, was shown to significantly potentiate the growth inhibitory effects of RG7388 and HDM201, and significantly increase the mRNA expression of p53 transcriptional target genes in a p53 ${ }^{\mathrm{WT}}$ cell line at a concentration that has no growth inhibitory effects as a single agent. RG7388, HDM201 and GSK2830371 failed to induce apoptosis as single agents; however, a combination treatment tipped cells into apoptosis from senescence. These data present the possibility of MDM2 and WIP1 inhibitor combinations as a potential treatment option for $\mathrm{p} 53^{\mathrm{WT}} \mathrm{uLMS}$ patients that warrants further investigation.

Keywords: RG7388/HDM201; GSK2830371; WIP1/PPM1D; MDM2; p53; Uterine Leiomyosarcoma; targeted therapy

\section{Introduction}

One of the main challenges facing clinicians when treating women with recurrent/ advanced uLMS, is the limited evidence for guiding systemic treatment options beyond primary debulking surgery. This, coupled with the fact that uLMS is rare, often discovered incidentally during routine hysterectomy for fibroids, and has high rates of relapse means that there is an urgent need to discover effective, targeted therapies. One potential area 
of interest is the pharmacological inhibition of the 'MDM2-p53 binding interaction' with low-molecular-weight MDM2 inhibitors. Several MDM2 inhibitors were developed that showed promise pre-clinically and are currently in early-phase clinical trials, although not specifically in uLMS patients [1-3]. If successful, these could provide a non-genotoxic alternative treatment option for $\mathrm{p} 53^{\mathrm{WT}} \mathrm{uLMS}$ patients.

The p53 protein is a tumour suppressor that, under normal conditions, is present in either its latent form or maintained by constant turnover at low levels [4]. However, in response to physiological stress, its half-life extends, resulting in the accumulation of p53 in the nucleus where it can act as a transcription factor [5,6]. As such it can bind to and activate the expression of a broad range of target genes, resulting in different cellular responses, including DNA repair, cell cycle arrest, senescence or apoptosis $[4,7,8]$. As p53 is the most frequently inactivated gene in human cancers, it has been extensively studied, both as a prognostic factor and as a potential therapeutic target for re-activation. The most common mutations are substitutions leading to a reduction or loss of function of p53. Some of the point missense mutations also result in the accumulation of a mutant protein, which, because of an altered conformation, is no longer recognised by its negative regulator, MDM2 [9-11].

Under normal physiological conditions, p53 levels are kept low, as it is constantly degraded by MDM2. MDM2 is a multi-functional protein, the main function of which is to act as an E3 ubiquitin ligase that binds to p53 at the N-terminus and ubiquinates several lysine residues in the C-terminal domain, targeting p53 for proteasomal degradation [12,13]. As the structural details of the binding between MDM2 and p53 were elucidated, and the importance of this interaction understood, preventing MDM2 from binding to p53 is actively pursued as a therapeutic strategy. MDM2 has a well-defined, small hydrophobic binding site for three key residues of p53. As such, there is a focus on developing lowmolecular-weight compounds that occupy this hydrophobic pocket, with a high affinity and specificity to prevent the binding interaction between p53 and MDM2 [14]. This allows the release and accumulation of WTp53 to carry out its growth inhibitory and/or pro-apoptotic functions.

RG7388 (Idasanutlin) and HDM201 (Siremadlin) are two small-molecular-weight MDM2 inhibitors that both had acceptable safety profiles in early-phase clinical trials. However, MDM2 inhibitor monotherapy may not be sufficient to achieve sustained clinical responses in cancer patients. In addition, resistance to single-agent treatment has emerged, possibly through the positive selection of p53-mutated clones [15]; therefore, combination treatments are being investigated. Combination therapy could improve efficacy and also reduce the risk of developing resistance.

PPM1D (Protein Phosphatase, $\mathrm{Mg}^{2+} / \mathrm{Mn}^{2+}$ Dependent, Delta Isoform), an oncogene that is commonly found to be overexpressed or amplified in $\mathrm{p} 53^{\mathrm{WT}}$ cancers, including breast and ovary [16-18], encodes the protein wild-type, p53-induced phosphatase 1 (WIP1), which is a direct transcriptional target of p53. However, WIP1 is also involved in the homeostatic regulation of p53 as, following cellular stress, WIP1 binds directly to p53 and dephosphorylates it at serine 15, thereby forming an auto-regulatory negative feedback loop [19]. WIP1 phosphatase activity also has a negative feedback regulatory effect on the upstream kinases that phosphorylated p53. In silico systems analysis modelling indicates that, following p53 activation, WIP1 may have an important role to play, along with MDM2 as an additional negative feedback regulator in the oscillatory behaviour of the p53 signalling network, and thus potentially in deciding cell fate. Modelling indicates that, at the single-cell level, treatment with an MDM2 inhibitor alone induces p53 in an oscillatory manner, resulting in cell cycle arrest, whereas cell death may require a state of sustained p53 activation. However, when MCF7 cells, modified with siRNA to knock down WIP1, were treated with Nutlin-3, the sustained activation of p53 was achieved resulting in a $\sim 90 \%$ cell death [20]. GSK2830371 is a small-molecule, allosteric inhibitor of WIP1 that inhibits its enzymatic activity and enhances its ubiquitin-mediated degradation [21]. Pre-clinical studies with a wide range of cell lines have shown in vitro that WIP1 inhibition 
with GSK2830371 potentiates the effect of MDM2 inhibitors in a p53-dependent manner, at concentrations where, as a single agent, it has limited effects [21-25].

Treatment with RG7388 or HDM201 alone may be limited by subsequent anti-apoptotic mechanisms; therefore, great effort was invested in combination strategies targeting the apoptosis pathway. Evading apoptosis is one of the hallmarks of cancer and can lead to chemotherapy resistance [26]. Therefore, therapeutic approaches that target negative regulators of apoptosis warrant investigation. The use of $\mathrm{BH} 3$ mimetics, small-molecule compounds that antagonise the anti-apoptotic BCL2 family proteins, which negatively regulate the intrinsic apoptosis pathway, are one such approach. BCL2, MCL-1 and BCL- $\mathrm{X}_{\mathrm{L}}$ the main anti-apoptotic proteins, were identified as cellular oncogenes, as they are frequently found to be overexpressed in human cancers and prevent normal or protective cell death mechanisms; therefore, there is a focus on developing inhibitors that have a high affinity and relative specificity for one or more members of this protein family [27-30].

Venetoclax, formally known as ABT-199, a potent and selective inhibitor of BCL2, gained FDA approval in 2016 for patients with chromosome 17 p deleted Chronic Lymphocytic Leukaemia (CLL). Interestingly, Hoffman-Luca et al. reported that Acute Myeloid Leukaemia (AML) cell lines that displayed resistance to MDM2 inhibitors retained sensitivity to BCL2 inhibitors [31], and Carter et al. reported the synergistic effects of an MDM2 BCL2 inhibitor combination in blast crisis Chronic Myeloid Leukaemia (CML) cells [32]. In 2018, encouraging results were presented from a phase $1 \mathrm{~b}$ trial investigating RG7388 in combination with Venetoclax in patients with AML. Resistance to the inhibition of BCL2 was overcome by inhibiting MDM2; cancer cells can become resistant to BCL2 inhibition by increasing the production of other anti-apoptotic proteins, such as MCL-1. MCL-1 is selectively targeted for proteasomal degradation, which then facilitates p53-mediated apoptosis, resulting in cell death [33]. More recently, in 2020, Decaudin et al. reported a synergistic combination between ABT263, a BCL2/ $\mathrm{X}_{\mathrm{L}} / \mathrm{W}$ inhibitor, and HDM201 in uveal melanoma cells and patient-derived xenografts [34].

MCL-1 specific inhibitors, however, proved challenging to design, and drug discovery/development pipelines displayed varying degrees of success, in part due to the large, rigid, hydrophobic, BH3-binding groove of MCL-1 [35]. MIM1, a highly specific low-molecular-weight inhibitor of MCL-1, demonstrated promise in preclinical studies by inducing apoptosis in leukaemia [36], glioblastoma [37], and melanoma cell lines [38]. This study presents novel results from investigations into the potential of GSK2830371, a WIP1 inhibitor; Venetoclax, a BCL2 inhibitor; and MIM1, an MCL-1 inhibitor, to potentiate the effects of MDM2 inhibitors RG7388 and HDM201 in p53 ${ }^{\mathrm{WT}}$ uLMS cells.

\section{Materials and Methods}

\subsection{Cell Lines and Reagents}

Cell lines were obtained from the American Type Culture Collection (ATCC) and authenticated by short-tandem repeat profiling (NewGene Ltd., Newcastle, UK). MES-SA and SK-UT-1 originate from the uterus and SK-LMS-1 the vulva. Cell lines were routinely cultured in Dulbecco's Modified Eagle's Medium (DMEM-D5796) supplemented with 10\% $(v / v)$ foetal calf serum and 1\% penicillin-streptomycin (SIGMA). Cell lines were routinely tested for mycoplasma infection. RG7388, HDM201 and Venetoclax were obtained from Selleckchem (Houston, TX, USA); GSK2830371 was purchased from SIGMA; and MIM1 BioTechne (Abingdon, UK). All compound stock solutions and serial dilutions were prepared in DMSO (SIGMA) and used in culture media at a final DMSO concentration of $0.5 \%$.

\subsection{Growth Inhibition Assay}

Exponentially growing cells were harvested and seeded in 96-well plates $24 \mathrm{~h}$ prior to the addition of either a single agent or combination treatment for $72 \mathrm{~h}$. Plates were fixed with cold Carnoy's fixative and left overnight at $4{ }^{\circ} \mathrm{C}$ to incubate. Plates were then washed with $\mathrm{dH}_{2} \mathrm{O}$, stained for 30 min with $0.4 \%(w / v)$ Sulforhodamine B (SRB) and dissolved in 1\% acetic acid. Plates were then washed 4 times with $1 \%$ acetic acid and left 
overnight to dry. An amount of $10 \mathrm{mM}$ Tris- $\mathrm{HCl} \mathrm{pH} 10.5$ was used to solubilise the stain and absorbance read at $570 \mathrm{~nm}$. GraphPad PRISM 9 was used to generate GI $_{50}$ values; the concentration at which $50 \%$ growth inhibition was achieved. For the dose-response matrix designs, cells were seeded and exposed to a range of drug concentration combinations; the effect on cell numbers after $72 \mathrm{~h}$ was determined as described above, then analysed using the SynergyFinder interactive web application to evaluate the response to drug combinations [39].

\subsection{Clonogenic Assay}

Cells were seeded in 6-well plates and left to adhere for $24 \mathrm{~h}$ before the drug of interest was added. $72 \mathrm{~h}$ later the medium containing drug was removed and replaced with fresh medium, then plates were left to incubate at $37^{\circ} \mathrm{C}$ for 14 days to assess colony forming ability. Following incubation, cells were fixed with Carnoy's fixative and stained using $0.4 \%$ crystal violet; colonies were counted using a DOT colony counter (IUL, Barcelona, Spain). Dose-survival curves and $\mathrm{LC}_{50}$ concentrations, the lethal concentration at which a $50 \%$ reduction in colony forming ability was achieved, were calculated using GraphPad PRISM 9.

\subsection{Western Immunoblotting}

Cells were seeded in 6-well plates at a density of $2.5 \times 10^{5} / \mathrm{mL}$ in $2 \mathrm{~mL}$ supplemented medium and left to adhere for $24 \mathrm{~h}$ before the drug of interest was added. After $24 \mathrm{~h}$, medium containing drug was removed and cells washed with $2 \mathrm{~mL}$ cold PBS. $40 \mu \mathrm{L}$ of sodium dodecyl sulfate (SDS) lysis buffer was added to each well and lysates collected. Lysates were heated at $100{ }^{\circ} \mathrm{C}$ for $10 \mathrm{~min}$, and then sonicated three times at amplitude 6.0 for $10 \mathrm{~s}$ using a MSE Soniprep 150 Plus ultrasonic disintegrator (Henderson Biomedical Ltd., Sydenham, UK). A Pierce ${ }^{\mathrm{TM}}$ BCA Protein Assay Kit (ThermoFisher Scientific, Cramlington, UK) was used to quantify the amount of protein in each lysate. From each assay, $35 \mu \mathrm{g}$ was then loaded onto a 12-well 4-20\% Mini-PROTEAN®TGXTM Gel (Bio-Rad, Hertfordshire, UK), the outside wells loaded with SeeBlue ${ }^{\mathrm{TM}}$ Pre-stained Protein Standard (Invitrogen, Cramlington, UK) and gel electrophoresis separation of the proteins performed at $180 \mathrm{~V}$ for $45 \mathrm{~min}$. The separated proteins were subsequently transferred to a Hybond-C nitrocellulose membrane by orthogonal electrophoresis at $100 \mathrm{~V}$ for $30 \mathrm{~min}$. The membrane was then blocked for $1 \mathrm{~h}$ in either $5 \%$ milk/TBS/Tween or BSA. The membrane was cut into three and each strip incubated in primary antibody overnight at $4{ }^{\circ} \mathrm{C}$. Membranes were washed in TBS/Tween then incubated with horseradish peroxidase (HRP) conjugated secondary antibodies at a 1:1000 dilution for $90 \mathrm{~min}$ at room temperature. Membranes were then subject to $4 \times 4$ min washes in TBS/Tween and imaged using a G:BOX XT4 Chemiluminescence and Fluorescence Imaging System (Syngene, Cambridge, UK), using Clarity Western Enhanced Chemiluminescence (ECL) Substrate (Bio-Rad, Hertfordshire, UK). To remove antibodies, membranes were then incubated in harsh stripping buffer $(20 \%(v / v)$ SDS, $12 \%(v / v) 0.5 \mathrm{M}$ Tris $\mathrm{HCl} \mathrm{pH} \mathrm{6.8,67 \%}(v / v)$ ultra-pure water and $1 \%(v / v)$ Beta-mercaptoethanol) in a water bath at $56{ }^{\circ} \mathrm{C}$ with agitation for $30 \mathrm{~min}$, before being washed twice with TBS/Tween. For re-probing with different antibodies, the membranes were blocked and the same procedure as mentioned above followed. For details of primary antibodies used see Table A1. Secondary antibodies were from Dako (Copenhagen, Denmark): polyclonal Goat Anti-Rabbit (PO448) and polyclonal Goat Anti-Mouse (PO447). Original western blots are included in Figures S1 and S2.

\subsection{Quantitative Reverse Transcriptase PCR}

An RNeasy Mini Kit (Qiagen 74104) was used in accordance with the manufacturer's instructions to isolate total RNA, which was then quantified using a NanoDrop ND-1000 Spectrophotometer (ThermoFischer Scientific, Cramlington, UK). A High-Capacity cDNA Reverse Transcription Kit (Applied Biosystems 4368814) was used to convert total RNA to single strand cDNA. To $10 \mu \mathrm{L}$ Master mix, $1 \mu \mathrm{g}$ of RNA was added, and the final 
volume made up to $20 \mu \mathrm{L}$ with $\mathrm{ddH}_{2} \mathrm{O}$. Samples were then incubated under the following conditions using a Gene Amp PCR system $2700: 25^{\circ} \mathrm{C}$ for $10 \mathrm{~min}, 37^{\circ} \mathrm{C}$ for $120 \mathrm{~min}$ hold, $85^{\circ} \mathrm{C}$ for $5 \mathrm{~s}$ then hold at $4{ }^{\circ} \mathrm{C}$. For the qRT-PCR reaction, SYBR green (Life Technologies, Glasgow, UK), primers (detailed in Table A2), cDNA (10 ng), and $\mathrm{dd}_{2} \mathrm{O}$ were added to make a final reaction volume of $10 \mu \mathrm{L}$, and then the plate was loaded into the QuantStudio 6 Flex Real-Time PCR System (Applied biosystems, Life Technologies, Glasgow, UK). GAPDH was used as the endogenous control and DMSO-vehicle-only-treated cells used as the reference calibrator. $R Q$ values were calculated using the formula $2^{\Delta \Delta C t}$, where $R Q$ expresses the fold change relative to the calibrator (DMSO).

\subsection{Caspase-Glo®3/7 Assay}

Cells were seeded in white 96-well plates (Greiner bio-one 655083) and left to adhere for $24 \mathrm{~h}$. Medium was removed and replaced with $50 \mu \mathrm{L}$ medium containing drug, and cells were incubated for $24 \mathrm{~h}$. Plates were then left to cool at room temperature for $10 \mathrm{~min}$ before adding $50 \mu \mathrm{L}$ Caspase-Glo 3/7 reagent (1:1 ratio). Plates were protected from light and left to incubate for $30 \mathrm{~min}$, before luminescence was measured on a FLUOstar Omega plate reader. All values were expressed as fold changes relative to DMSO treated control.

\subsection{Statistical Analysis}

Data are presented as the mean \pm standard error mean (SEM) of three independent repeats unless otherwise stated. All statistical analyses were conducted using GraphPad PRISM 9 with a $p$-value $\leq 0.05$ considered significant.

\section{Results}

\subsection{RG7388 and HDM201 Are Potent Inhibitors in $p 53^{W T} u L M S$ Cells but Not $p 53^{M U T}$}

The $\mathrm{p} 53^{\mathrm{WT}}$ cell line MES-SA exhibited a dose-dependent response to inhibition with RG7388 and HDM201, with GI $_{50}$ values in the nanomolar range, $126 \pm 10.07 \mathrm{nM}$ and $60 \pm 4.62 \mathrm{nM}$, respectively (Figure 1A). MES-SA also displayed a reduction in clonogenic cell survival in response to inhibition with RG7388 and HDM201, with $\mathrm{LC}_{50}$ values also in the nanomolar range: $14.0 \pm 1.0 \mathrm{nM}$ and $18.0 \pm 4.2 \mathrm{nM}$, respectively (Figure 1B). HDM201 was significantly more potent than RG7388 in growth inhibition assays- $p=0.0037$ (unpaired $t$-test) - but not in clonogenic survival assays, as no significant difference between the two inhibitors was found. Both p53 ${ }^{\mathrm{MUT}}$ cell lines, SK-UT-1 and SK-LMS-1, were resistant to RG7388 up to $10 \mu \mathrm{M}$ and HDM201 up to $30 \mu \mathrm{M}$. Interestingly, SK-UT-1 showed a sensitivity towards RG7388 at the highest dose of $30 \mu \mathrm{M}$, with a GI 50 value of $16.3 \pm 0.9 \mu \mathrm{M}$, while SK-LMS-1 remained resistant, indicating that HDM201 had a higher specificity than RG7388 for its MDM2 target, and thus may be less likely to cause off-target effects in patients. However, in clonogenic survival assays, SK-UT-1 displayed resistance to both RG7388 and HDM201 of up to $10 \mu \mathrm{M}$, suggesting that even if proliferation is temporarily impaired the replicative potential is not, and that given time, cells are able to recover and continue to proliferate. 
A

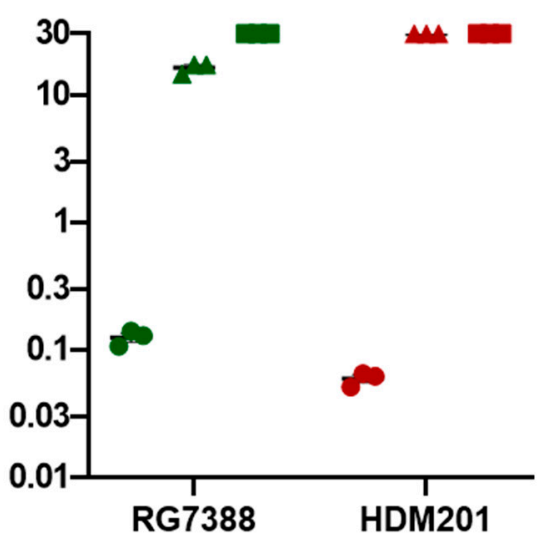

- MES-SA

- SK-UT-1

- SK-LMS-1

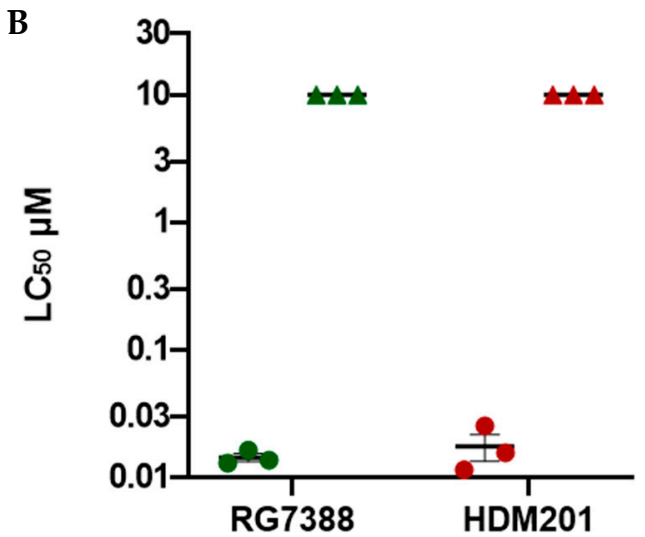

Figure 1. Summary values from growth inhibition and cytotoxicity assays for LMS cell lines treated for $72 \mathrm{~h}$ with MDM2 inhibitors, RG7388 and HDM201. (A) SRB assay was used to determine $\mathrm{GI}_{50}$ values. For SK-UT-1 treated with HDM201, and SK-LMS-1 treated with both RG7388 and HDM201, no $\mathrm{GI}_{50}$ value was reached up to the maximum tested dose of $30 \mu \mathrm{M}$; (B) $\mathrm{LC}_{50}$ values generated from clonogenic survival assays for MES-SA and SK-UT-1 against RG7388 and HDM201. For SK-UT-1, no $\mathrm{LC}_{50}$ was reached up to the maximum tested dose of $10 \mu \mathrm{M}$. Data represent three independent repeats with mean \pm SEM.

\subsection{GSK2830371 Has No Growth Inhibitory Effects as a Single Agent}

No or minimal growth inhibition was observed for doses $\leq 10 \mu \mathrm{M}$ in all cell lines; however, for SK-LMS-1 at $30 \mu \mathrm{M}$ there was evidence of a growth inhibition with a $\mathrm{GI}_{50}$ value of $27.7 \pm 1.6 \mu \mathrm{M}$ (Figure 2A). Clonogenic survival assays also revealed no evidence of cytotoxicity in all cell lines up to doses of $3 \mu \mathrm{M}$. For both p53 ${ }^{\text {MUT }}$ SK-UT-1 and SK-LMS-1 cell lines, there was slight inhibition at 10 and $30 \mu \mathrm{M}$, respectively; but for p53 ${ }^{\mathrm{WT}}$ MES-SA, there was a dose-dependent inhibition by GSK2830371, with an $\mathrm{LC}_{50}$ value of $8.2 \pm 0.4 \mu \mathrm{M}$ (Figure 2B). A sub-growth-inhibitory dose of $2.5 \mu \mathrm{M}$ GSK2830371 was chosen for the initial evaluation of combination studies with MDM2 inhibitors.

A

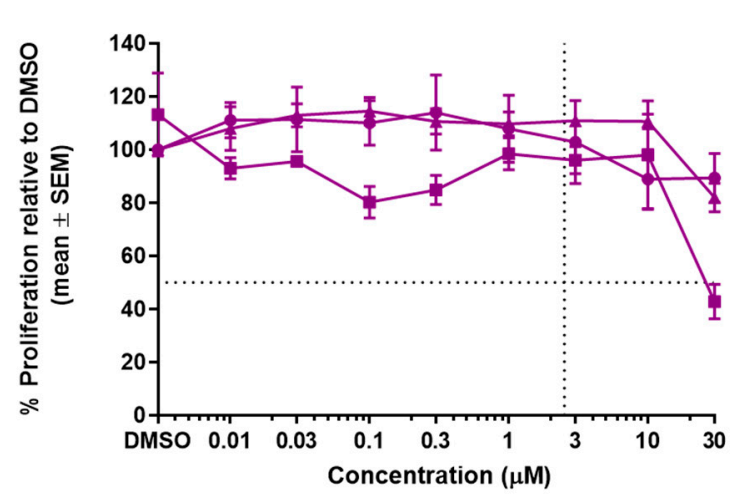

B

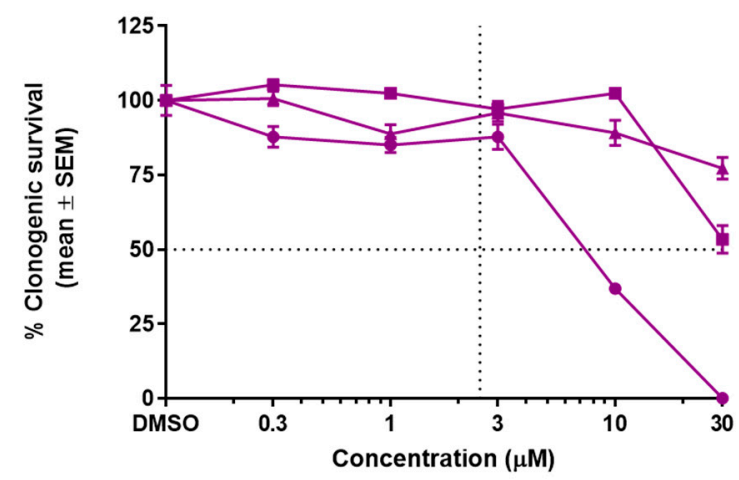

Figure 2. Growth inhibitory and cytotoxic effects of GSK2830371 as a single agent on LMS cell lines. Dashed lines highlight $2.5 \mu \mathrm{M}$ and 50\% proliferation/clonogenic survival. (A) Dose-response curves following $72 \mathrm{~h}$ incubation with GSK2830371 (SRB assay); (B) dose-response curves from clonogenic survival assays used to determine $\mathrm{LC}_{50}$ concentrations. Cells were treated for $72 \mathrm{~h}$ then left to incubate for 14 days. Data points represent the mean \pm SEM of three independent repeats.

\subsection{WIP1 Inhibitor GSK2830371 Potentiates the Growth Inhibitory and Cytotoxic Effects of MDM2 Inhibitors on uLMS $p 53^{W T}$ Cells}

GSK2830371, at a dose of $2.5 \mu \mathrm{M}$, which had no effect on proliferation, was found to significantly potentiate growth inhibition when combined with RG7388 (Figure 3A) and 
HDM201 (Figure 3B); GI $_{50}$ values were significantly reduced in combination treatments, $p<0.05$ as determined by a paired $t$-test, (Figure 3I). Clonogenic assays were then performed to assess the capability of GSK2830371 to potentiate the cytotoxic effects of RG7388 and HDM201. Whilst colony formation was inhibited following a combination treatment with RG7388 (Figure 3C), and HDM201 (Figure 3D), the reduction in $\mathrm{LC}_{50}$ values was not significant: $p=0.08$ and $p=0.06$, respectively (Figure 3J). The p53 ${ }^{\mathrm{MUT}}$ SK-UT- 1 cells, previously shown to be resistant to RG7388 or HDM201 as single agents, demonstrated only a small combination effect in both growth inhibitions (Figure $3 \mathrm{E}, \mathrm{F}$ ) and clonogenic assays (Figure 3G,H).

MES-SA

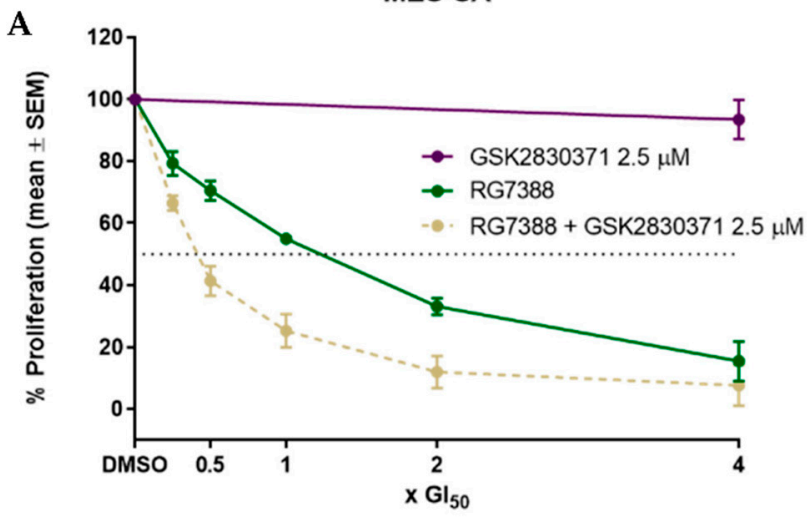

C

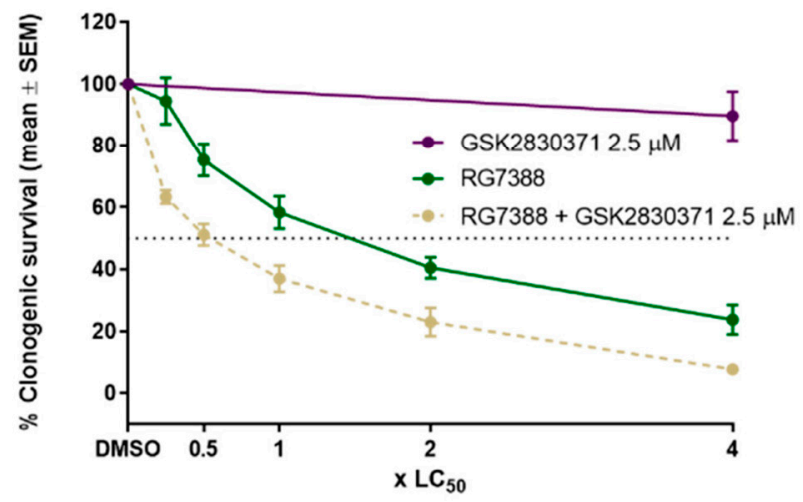

E

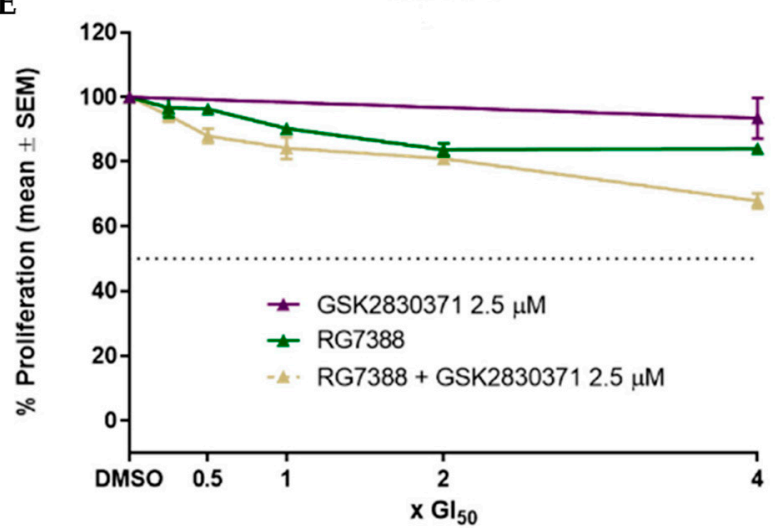

MES-SA

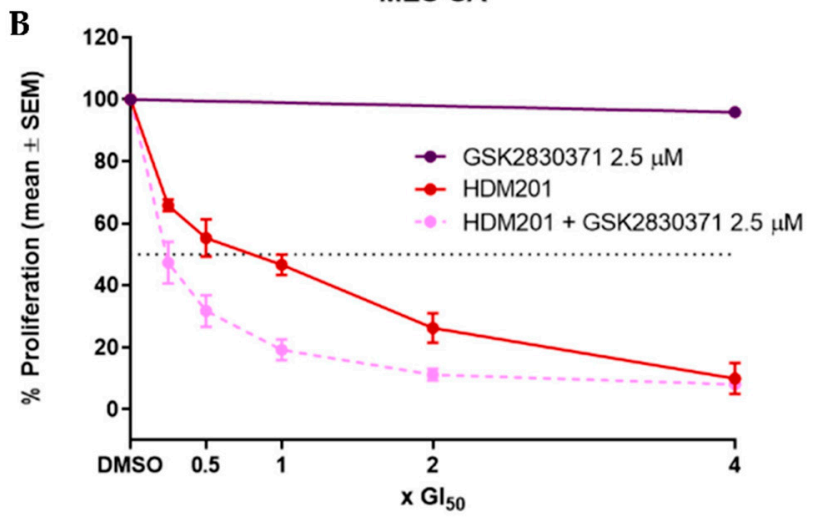

D

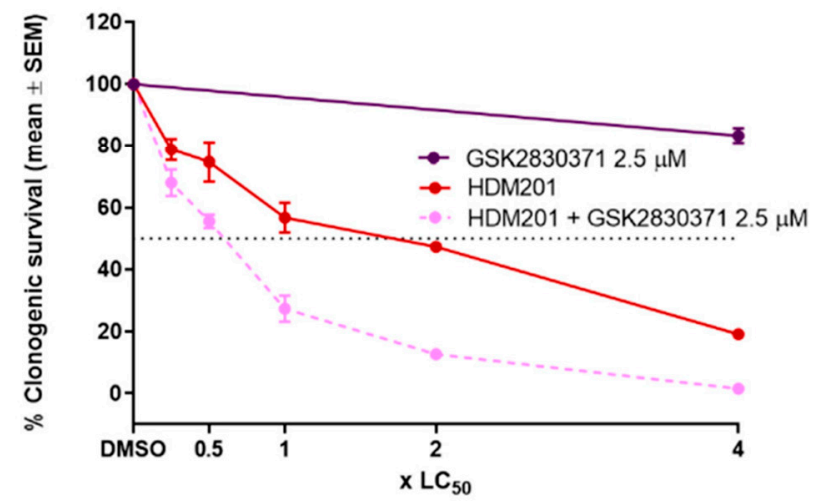

SK-UT-1

F

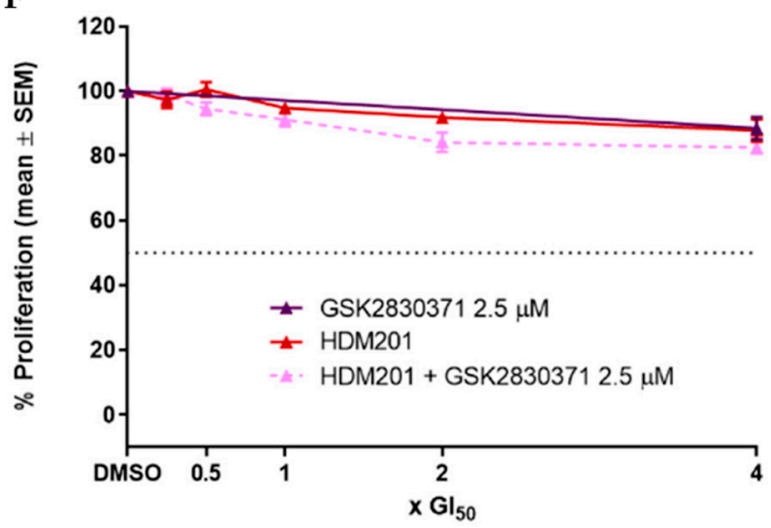

Figure 3. Cont. 
G

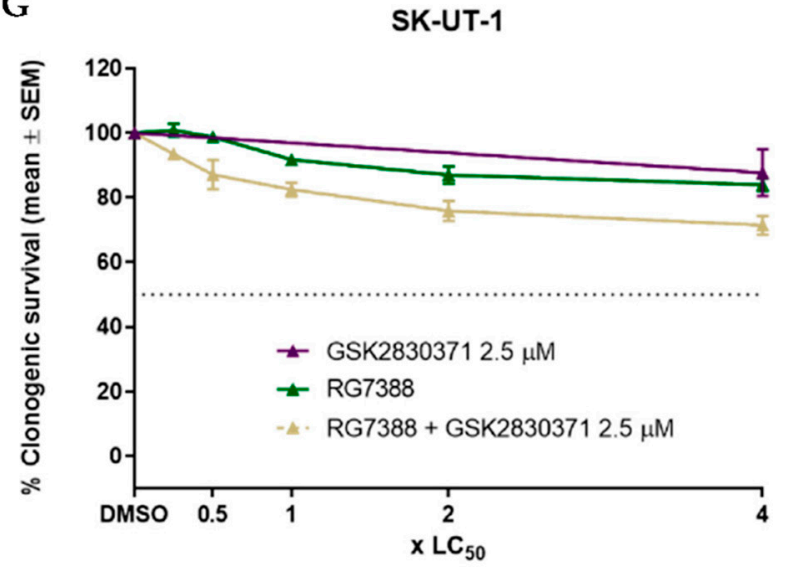

I

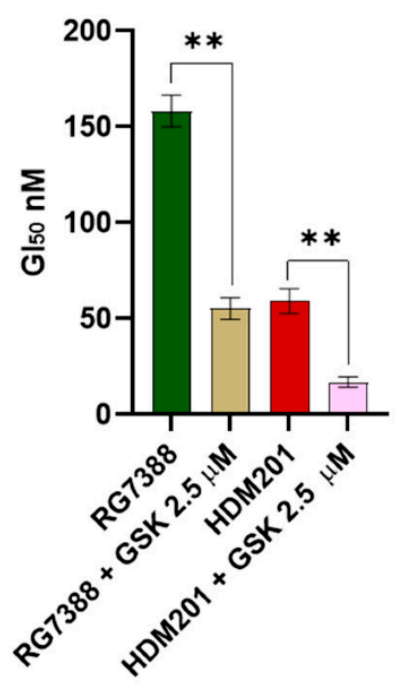

$\mathbf{H}$

SK-UT-1

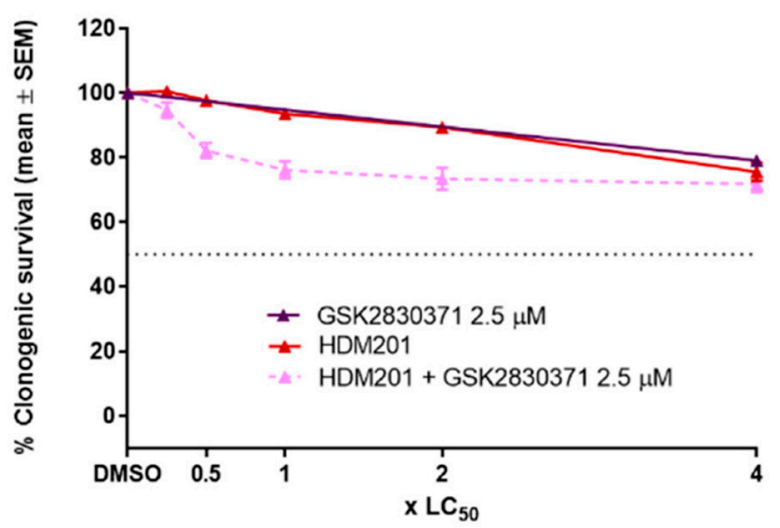

J

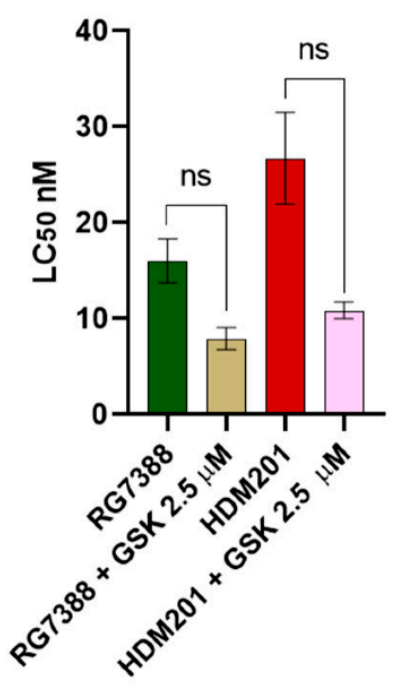

Figure 3. Effects of MDM2 inhibitors in combination with $2.5 \mu \mathrm{M}$ GSK2830371 on cell proliferation and clonogenic survival. Percentage proliferation or clonogenic survival are expressed relative to DMSO-treated control. Growth inhibition curves for MES-SA cells treated with $2.5 \mu \mathrm{M}$ GSK2830371 and (A) RG7388; (B) HDM201; Dose-response curves following clonogenic survival assays for MES-SA cells treated with $2.5 \mu$ M GSK2830371 and (C) RG7388; (D) HDM201; (E-H) the same as (A-D) but for p53 mutant SK-UT-1 cells; (I) GI 50 values for MES-SA when treated with single-agent MDM2 inhibitor or combination with $2.5 \mu \mathrm{M}$ GSK2830371 as determined from growth inhibition assays in (A,B); (J) LC 50 values for MES-SA when treated with single-agent MDM2 inhibitor or combination with $2.5 \mu \mathrm{M}$ GSK2830371, as determined from clonogenic survival assays in (C,D). Statistical significance was evaluated using a paired $t$-test, ${ }^{* *}=p<0.01$. GSK, GSK2830371; ns, not significant.

Western blot analysis (Figure 4) was used to investigate the effect of combination treatment on the p53 molecular signalling pathway. MES-SA cells were treated for $6 \mathrm{~h}$ with RG7388 or HDM201 at $10 \times$ their respective GI $_{50}$ concentrations, GSK2830371 at $2.5 \mu \mathrm{M}$, or a combination. As single agents, both MDM2 inhibitors induced p53 stabilisation and the upregulation of p21 (p21 WAF1, CDKN1A); therefore, confirming the functional activation of wild-type p53. GSK2830371 as a single agent did not induce p53 stabilisation. Combination treatment, however, led to an increased p53 stabilisation with increased levels of the p53 transcriptional targets, MDM2 and p21. An increase in phosphorylated p53 (pp53) was also observed with combination treatment and this correlated with the decrease in levels of WIP1, which, when present, acted to dephosphorylate and negatively regulate pp53. Upon inhibiting WIP1, there was also a decrease in the levels of full-length PARP-1 and 
an increase in PUMA, both suggesting that apoptotic signals increased compared to the single-agent treatment.

A

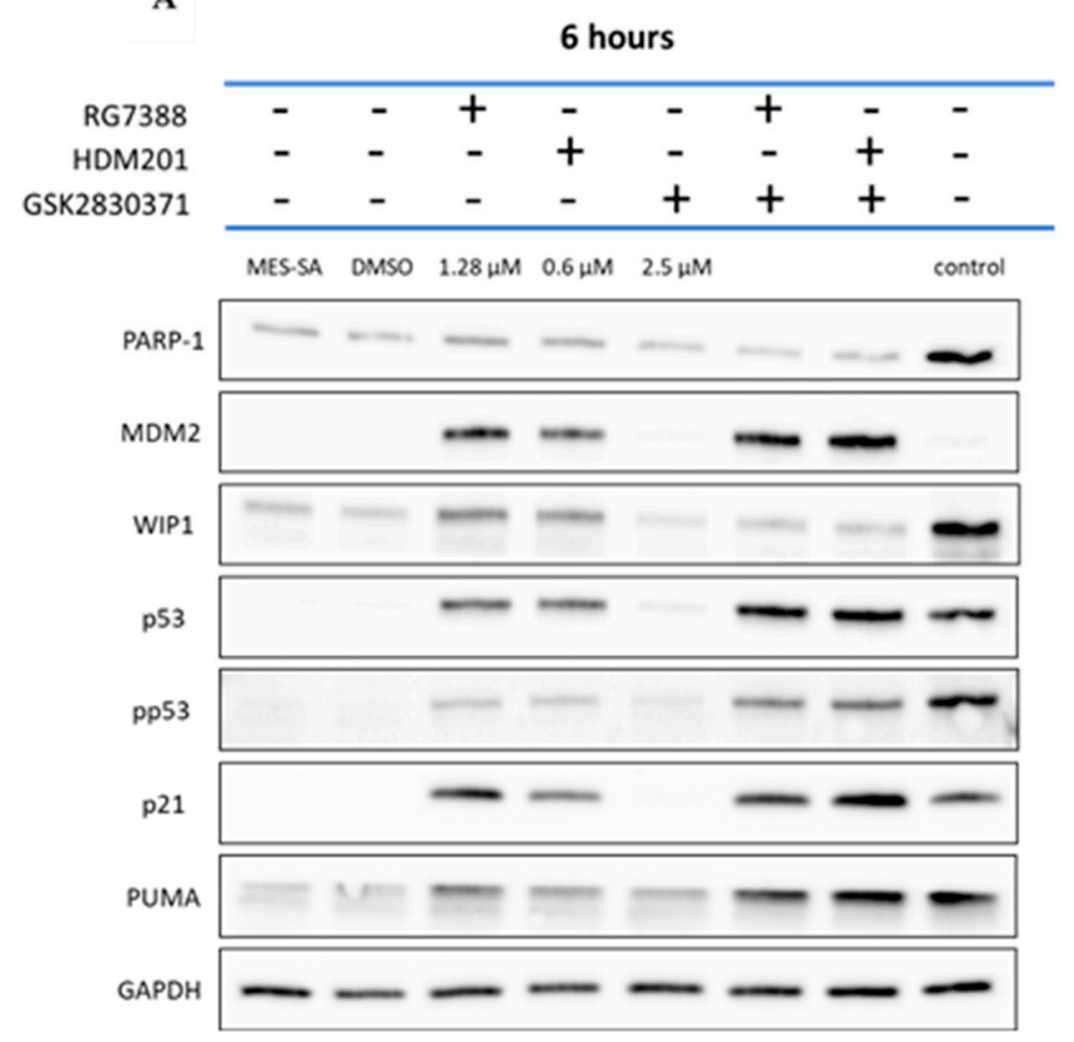

B

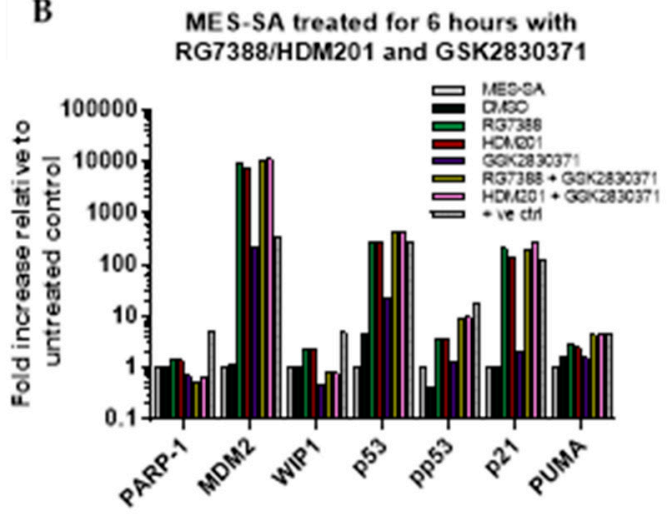

Figure 4. (A) Western immunoblot of MES-SA cells treated for $6 \mathrm{~h}$ with RG7388, HDM201 and GSK2830371. The positive control was SH5Y5Y cells collected $2 \mathrm{~h}$ post $4 \mathrm{~Gy}$ X-irradiation (provided by A. Yagbasan). GAPDH was used as the loading control. Doses of RG7388 and HDM201 represent $10 \times$ their $\mathrm{GI}_{50}$ concentrations. All strips were from the same membrane which was cut into three. The top strip was probed for WIP1, MDM2 and PARP-1; the second for pp53, p53 and GAPDH; and the third PUMA and p21. (B) Densitometry, with values background corrected, normalised to GAPDH, then fold change expressed relative to untreated control.

\subsection{Strong Synergy Observed with MDM2 Inhibitors in Combination with GSK2830371}

A dose-response matrix design was used to explore a wider range of combination concentrations to establish the dose of RG7388 or HDM201 that caused the greatest synergy when used in combination with GSK2830371, as determined by the Zero Interaction Potency (ZIP) Model. Both MDM2 inhibitor combinations were considered synergistic with overall synergy scores $>10$. For both combinations, RG7388 + GSK2830371 (Figure 5A,B) and HDM201 + GSK2830371 (Figure 5C,D), there was a statistically significant difference between the overall and highest synergy scores recorded $(14.63 \pm 0.12$ vs. $23.45 \pm 2.52$ for RG7388 + GSK2830371 $p=0.0188$ and $16.37 \pm 1.35$ vs. $27.64 \pm 1.25$ for HDM201 + GSK2830371 $p=0.0079)$, highlighting the importance of optimal dose selection for combination studies. The strongly synergistic effect with GSK2830371 was observed to the same extent for both MDM2 inhibitors, suggesting that there was an in-class drug effect. Heatmaps, generated by SynergyFinder, indicated that, for both combinations, the area where the greatest synergy was observed was between 30-100 nM, for either MDM2 inhibitor, and 2.5-3.5 $\mu \mathrm{M}$ for GSK2830371, where 80-90\% inhibition was achieved. Importantly, these results are seen in doses of the MDM2 inhibitor that can be achieved clinically [40]. 


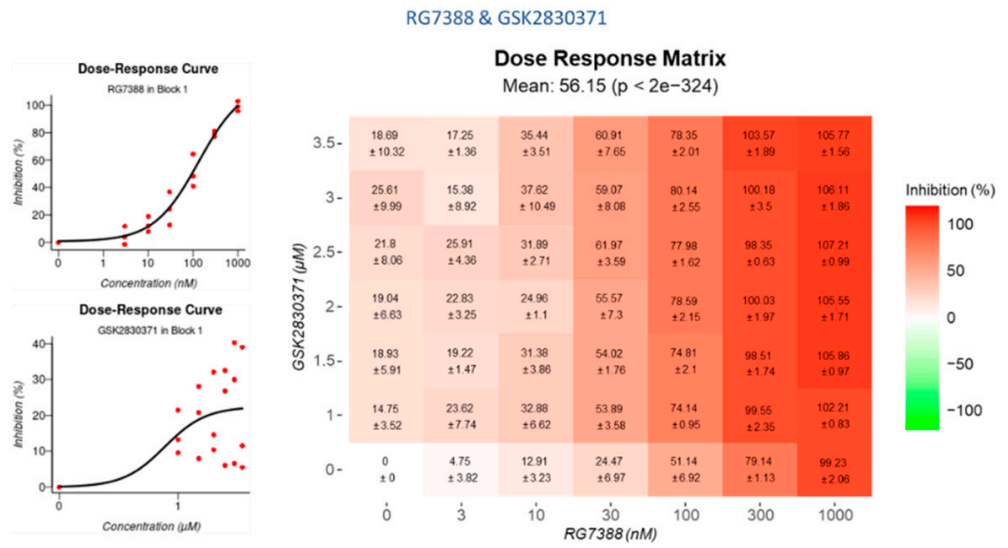

B
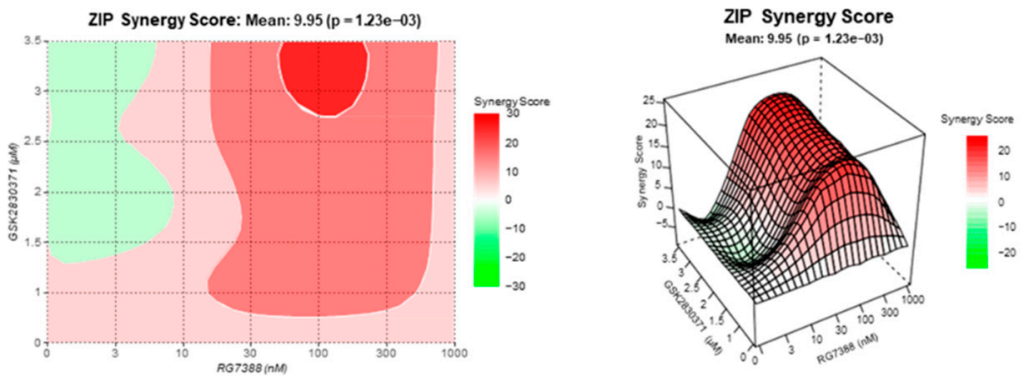

HDM201 \& GSK2830371

C

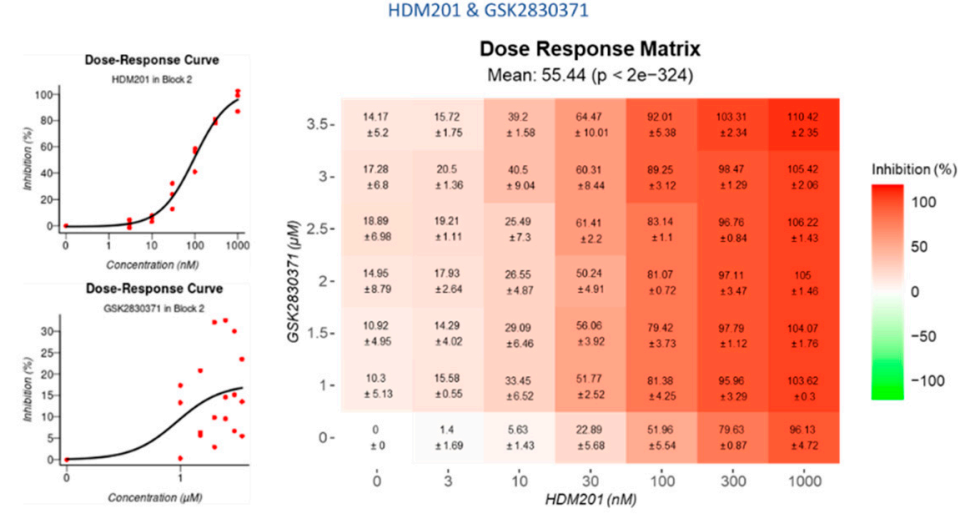

$\mathrm{D}$
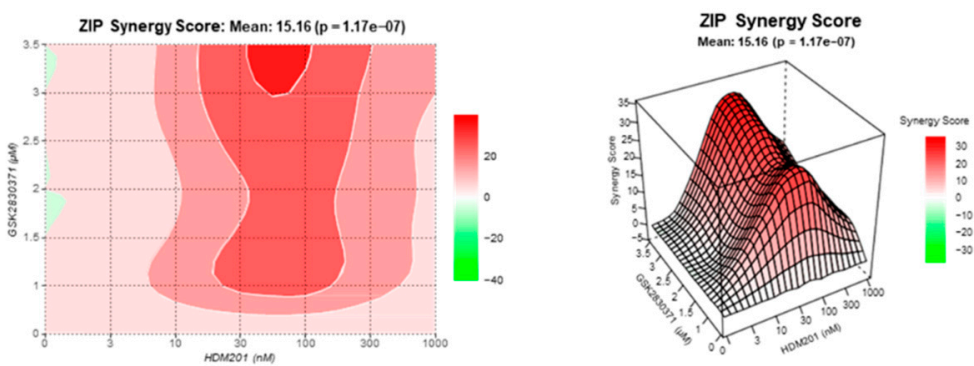

Figure 5. Synergy plots for MDM2/WIP1 inhibitor combination. A dose-response matrix design was used to assess synergy and determine doses at which the greatest synergy was observed, as determined by the Zero Interaction Potency (ZIP) Model. MES-SA cells were treated with either RG7388 or HDM201 and $2.5 \mu \mathrm{M}$ GSK2830371 for $72 \mathrm{~h}$ then growth inhibition was assessed using SRB assay. Dose-response curves, dose-response matrix and synergy plots for RG7388 and GSK2830371 (A,B), and for HDM201 and GSK2830371 (C,D). 
3.5. Combination with GSK2830371 Induces Irreversible Growth Arrest Following $72 \mathrm{~h}$ Treatment of $p 53^{W T}$ uLMS Cells with $n M$ Concentrations of MDM2 Inhibitors

The IncuCyte incubator camera system was used to capture phase contrast images every $4 \mathrm{~h}$ to accurately determine confluency following either $72 \mathrm{~h}$ treatment or continual exposure for $288 \mathrm{~h}$. The medium was replaced every $72 \mathrm{~h}$. MES-SA cells recovered their ability to proliferate following exposure to RG7388 (Figure 6A) or HDM201 (Figure 6B) for $72 \mathrm{~h}$ at 1,4 and $10 \times \mathrm{GI}_{50}$ concentrations, although growth was retarded and delayed. However, when MES-SA cells were continually dosed with either RG7388 (Figure 6A) or HDM201 (Figure 6B) they were unable to regrow at any dose, the only exception being RG7388 at $1 \times$ GI $_{50}$ concentration. A $72 \mathrm{~h}$ treatment with $2.5 \mu \mathrm{M}$ GSK2830371 had little to no effect on the overall proliferation but did initially slow cell growth (Figure 6C). A similar effect was observed when cells were continuously dosed with GSK2830371, only to a greater extent when $\sim 80 \%$ overall confluency was reached (Figure $6 \mathrm{C}$ ). In marked contrast to the reversible growth inhibition with MDM2 inhibitor alone, when treated for $72 \mathrm{~h}$ with either RG7388 (Figure 6D) or HDM201 (Figure 6E) in combination with $2.5 \mu \mathrm{M}$ GSK2830371, cells were unable to regrow again at any dose, with only one exception: RG7388 + GSK2830371 at $1 \times$ GI $_{50}$ dose of RG7388. These results highlight the potential of this treatment combination, as the addition of $2.5 \mu \mathrm{M}$ GSK2830371 to low doses of MDM2 inhibitors, $4 \times \mathrm{GI}_{50}$, can generate the same growth inhibitory effects following $72 \mathrm{~h}$ treatment that can only be achieved through continual dosing with the MDM2 inhibitors as single agents.

A

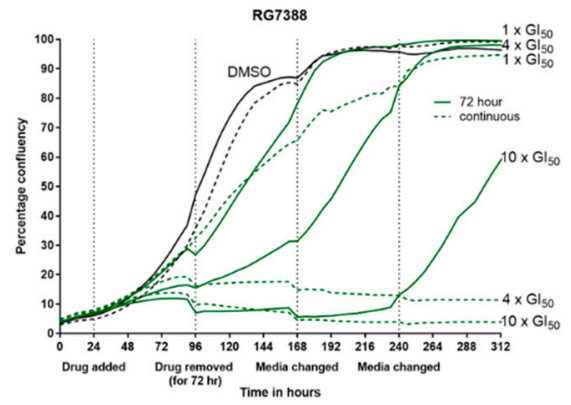

D

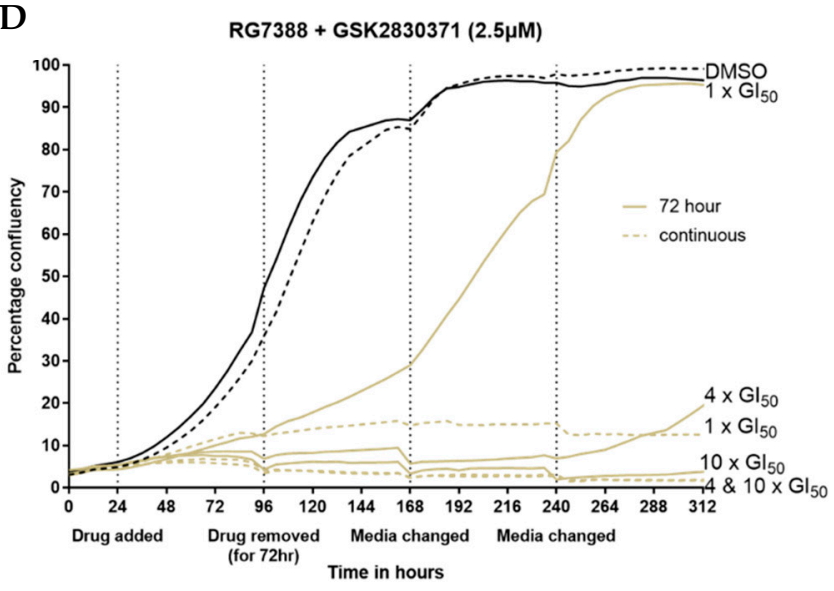

C

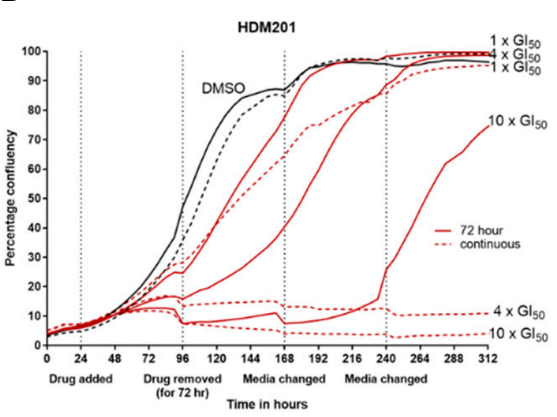

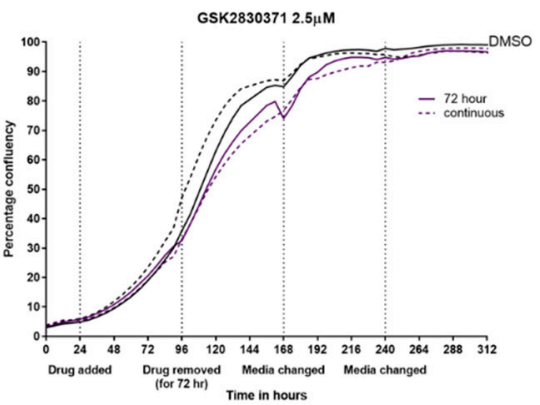

E

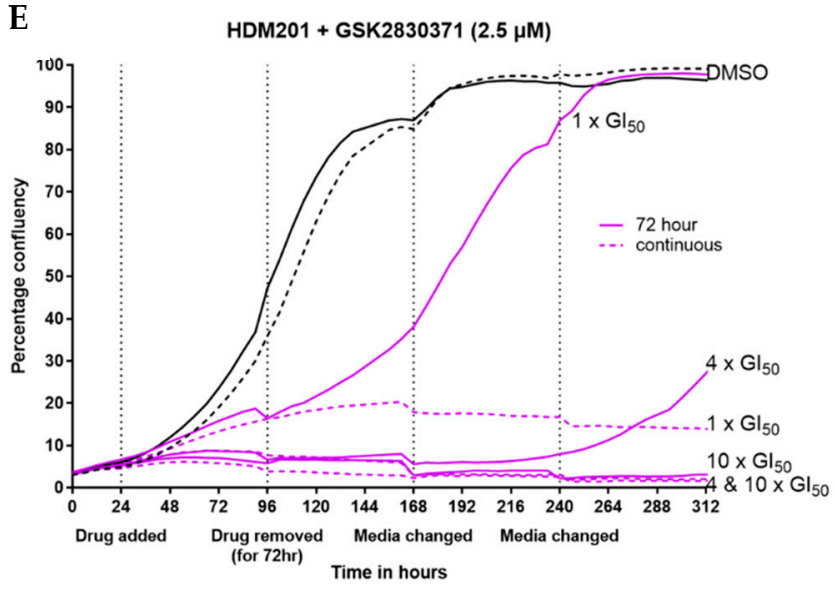

Figure 6. Cont. 
$\mathbf{F}$

G
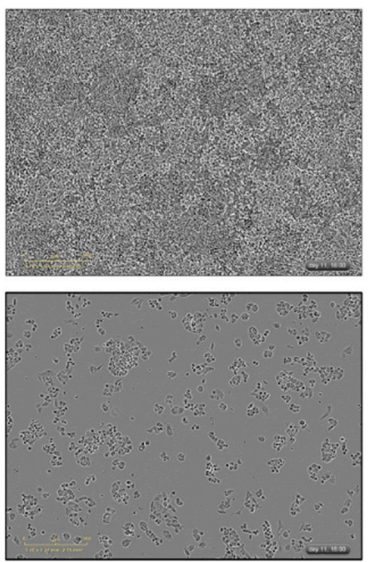

$\mathbf{H}$

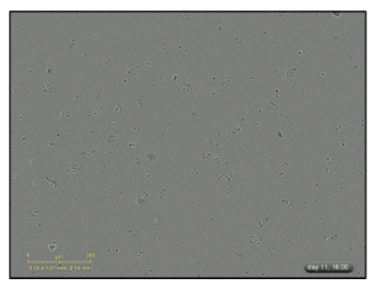

I

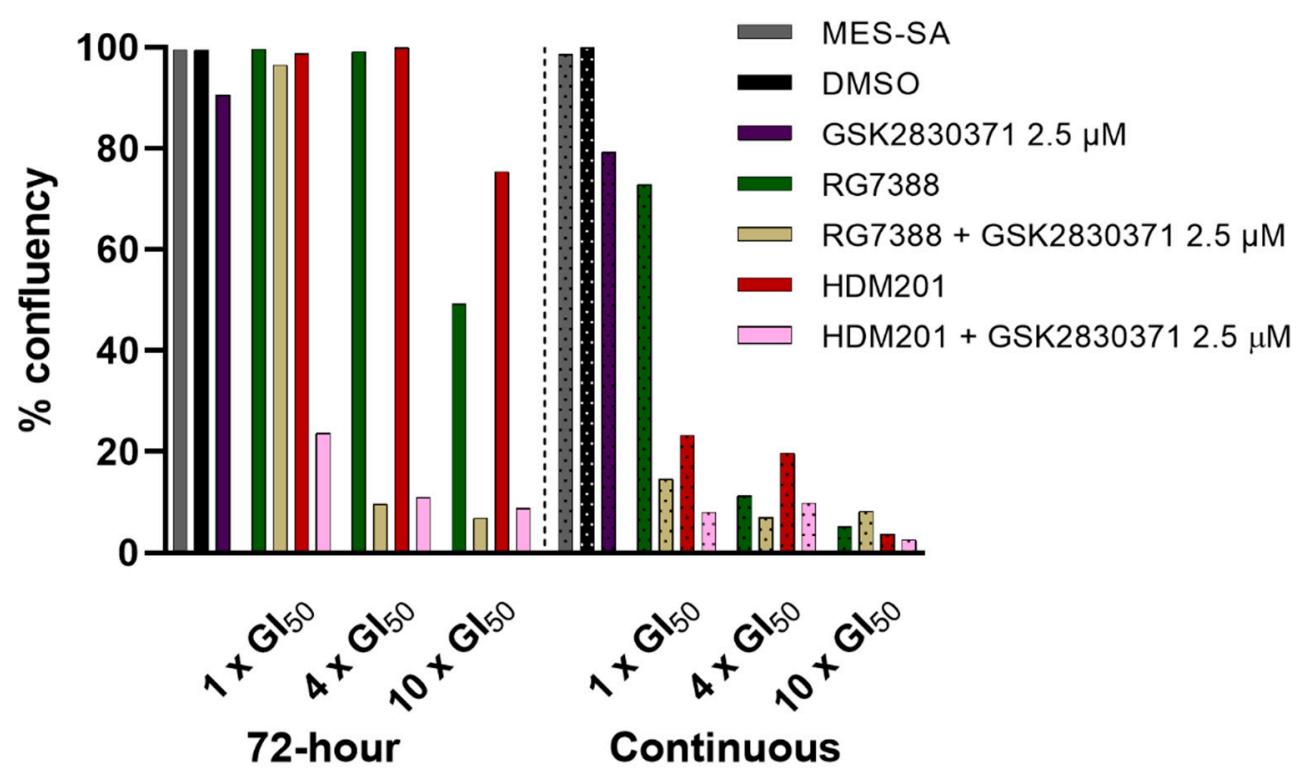

Figure 6. Images and confluency data captured using the IncuCyte incubator camera system. MES-SA cells were treated with drug for either $72 \mathrm{~h}$ or continually dosed for $288 \mathrm{~h}$. Medium was replaced every $72 \mathrm{~h}$ and phase contrast images taken every $4 \mathrm{~h}$. Growth curves for (A) RG7388; (B) HDM201; (C) GSK2830371; (D) RG7388 + GSK2830371; (E) HDM201 + GSK2830371, with solid lines representing $72 \mathrm{~h}$ treatment and dashed lines continual treatment; representative phase contrast images taken on day 11 at 18:00 h for (F) DMSO treatment for $72 \mathrm{~h}$; (G) RG7388 at $10 \times \mathrm{GI}_{50}$ concentration for $72 \mathrm{~h}$; (H) RG7388 at $10 \times \mathrm{GI}_{50}+2.5 \mu \mathrm{M}$ GSK2830371 treatment for $72 \mathrm{~h}$; (I) percentage confluency of each well following either $72 \mathrm{~h}$ or continual treatment with 1,4 or $10 \times \mathrm{GI}_{50}$ concentrations of RG7388 or HDM201, alone or in combination with $2.5 \mu$ M GSK2830371. Percentage confluency of each well was calculated using an integrated confluence algorithm and reflects both cell number and area of the well covered by cells.

\subsection{Combined MDM2 and WIP1 Inhibition Significantly Increases Transcript Levels of Pro-Apoptotic Genes in $p 53^{W T}$ uLMS Cells}

To determine if combination treatment also enhanced the transcriptional activity of p53, qRT-PCR was used to investigate the mRNA expression levels of selected p53 transcriptional target genes involved in cell cycle arrest and apoptosis. MES-SA and SK-UT1 were treated with $1 \mu \mathrm{M}$ RG7388 or $1 \mu \mathrm{M}$ HDM201 alone or in combination with $2.5 \mu \mathrm{M}$ GSK2830371 for $6 \mathrm{~h}$. All statistically significant fold changes, as determined by a 2-way ANOVA with Tukey's post hoc test, are listed in Table A3 for MES-SA and Table A4 for SKUT-1; Figure 7 only displays those between RG7388 and HDM201 single-agent treatments and the combination with $2.5 \mu \mathrm{M}$ GSK2830371. Consistent with their p53 mutational status, fold changes observed in SK-UT-1, p53 ${ }^{\mathrm{MUT}}$, (Figure 7B) were much lower than in MES-SA, p53 ${ }^{\mathrm{WT}}$ (Figure 7A). For both MES-SA and SK-UT-1 there was little to no change in the transcript levels of TP53 itself, or of the anti-apoptotic gene BCL2 following any treatment. For MES-SA, BCL2L11 also remained unchanged, as did MDM2, PUMA, FAS, BID, and PPM1D for SK-UT-1. Generally, there was clear induction of p53 target genes following the treatment with either RG7388 or HDM201, which was further increased with the addition of $2.5 \mu \mathrm{M}$ GSK2830371 in MES-SA, but not SK-UT-1. 
A
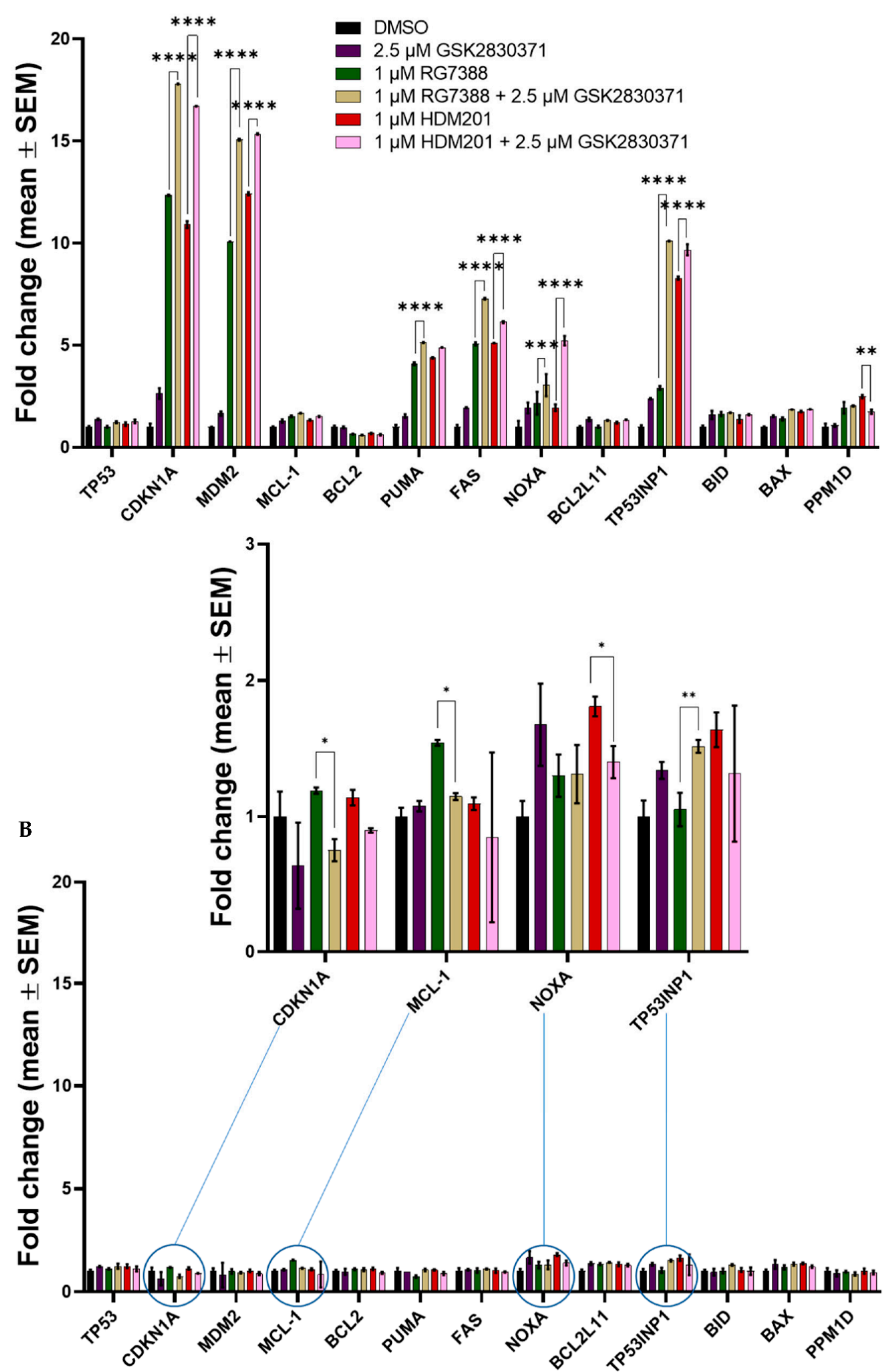

Figure 7. Fold change in mRNA expression of selected p53 transcriptional target genes following $6 \mathrm{~h}$ treatment with either single agent RG7388, HDM201, $2.5 \mu \mathrm{M}$ GSK2830371 or a combination in (A) MES-SA; (B) SK-UT-1. GAPDH was used as the endogenous control and DMSO-treated cells were used as the calibrator between repeats. RQ values were calculated using the formula $2^{\Delta \Delta C t}$. Bars represent the mean \pm SEM. Statistical significance was determined by two-way ANOVA with Tukey's post hoc test for multiple comparisons, significance taken at $p<0.005$. Only significant changes between single-agent MDM2 inhibitor treatment and the combination with $2.5 \mu \mathrm{M}$ GSK2830371 are displayed on the graphs. All others are listed in Table A3 for MES-SA and A4 for SK-UT-1. ${ }^{*} p \leq 0.05$, ${ }^{* *} p \leq 0.01,{ }^{* * *} p \leq 0.001,{ }^{* * * *} p \leq 0.0001$. 
For MES-SA, CDKN1A (a gene involved in cell cycle control, the inhibition of proliferation and implicated in senescence), MDM2, and pro-apoptotic genes, FAS, NOXA, and TP53INP1 were all induced to significantly higher levels following combination treatment with GSK2830371, compared to treatment with either MDM2 inhibitor alone. Surprisingly, $P P M 1 D$ was the only gene whose expression was significantly reduced following combination treatment with $2.5 \mu \mathrm{M}$ GSK2830371 compared to HDM201 single-agent treatment. Transcript levels of the PUMA pro-apoptotic gene were also increased following combination treatment; however, the difference was only significant for RG7388 and GSK2830371. $B I D, B C L 2 L 11$, and $B A X$, pro-apoptotic genes involved in the initiation and regulation of the intrinsic apoptosis pathway, showed only a modest induction compared with other p53 target genes, with no significant difference between any of the treatment options. These results are consistent with previous studies showing either no or modest induction of $B A X$ following treatment with MDM2 inhibitors (RG7388 and Nutlin-3a) in a panel of ovarian or cutaneous melanoma cell lines, respectively [25,41]. Interestingly, treatment with $2.5 \mu \mathrm{M}$ GSK2830371 alone significantly induced some of the p53 transcriptional target genes: CDKN1A, MDM2, FAS, NOXA, TP53BP1 and BID, although the induction was relatively small with none greater than 3 -fold. When considered alongside the earlier described results showing that $2.5 \mu \mathrm{M}$ GSK2830371 treatment alone had little to no effect on cell proliferation, this indicates that such small changes are below the threshold required for a functional impact.

For the $\mathrm{p} 53^{\mathrm{MUT}}$ SK-UT-1 cells, any changes in expression were modest, with no greater than a 2-fold induction over DMSO control. However, it was interesting to note that the statistical differences found between single-agent MDM2 treatment and combination treatment with $2.5 \mu \mathrm{M}$ GSK2830371 were reductions in transcriptional activity, except for TP53INP1.

\subsection{GSK2830371 Combination with MDM2 Inhibitors Induces Apoptosis}

As the transcriptional activity of several pro-apoptotic genes was significantly enhanced in p53 ${ }^{\mathrm{WT}}$ cells following combination treatment, the catalytic activity levels of caspases 3 and 7 were assessed to test whether this resulted in increased caspase-3/7dependent apoptosis. MES-SA cells were treated for $24 \mathrm{~h}$ with either single-agent MDM2 inhibitor at 1 or $10 \times \mathrm{GI}_{50}$ concentrations (10 $\times$ only for Western blot analysis), single-agent GSK2830371 at $2.5 \mu \mathrm{M}$ or a combination of both (Figure 8), then the levels of activity for caspases 3 and 7 were determined using a Caspase-Glo-3/7 assay (Figure 8A), or levels of cleaved-PARP and cleaved-caspase-3 tested using Western immunoblotting (Figure 8B,C). Neither of the MDM2 inhibitors showed evidence of induced caspase-3/7 activity at 1 or $10 \times \mathrm{GI}_{50}$ concentrations, nor did $2.5 \mu \mathrm{M}$ GSK2830371 alone. Interestingly, however, combination treatment led to a significant increase in the levels of caspase-3/7 activity detected with HDM201 at either 1 or $10 \times \mathrm{GI}_{50}$ concentrations $(p<0.001)$ but only at $10 \times$ for RG7388 $(p<0.0001)$. Western blot analysis showed an increase in both cleaved-PARP and cleaved-caspase- 3 following combination treatment, when compared to single-agent treatment alone, indicating that the apoptosis induced by combination treatment is caspase dependent, supporting the caspase- $3 / 7$ catalytic activity data. 
A

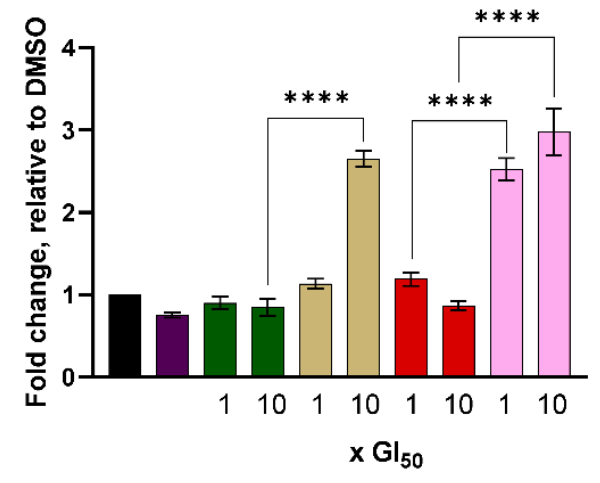

B

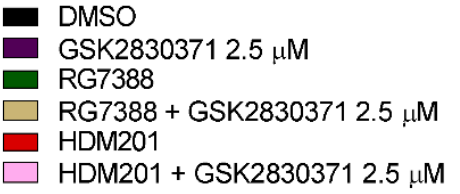

C

\section{4 hours}

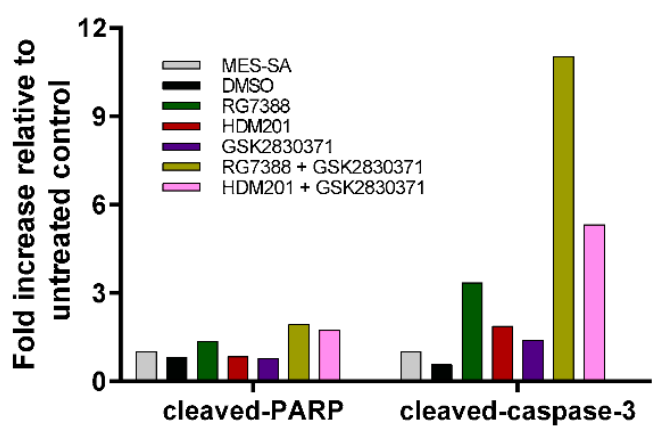

MES-SA treated for 24 hours with RG7388/HDM201 and GSK2830371

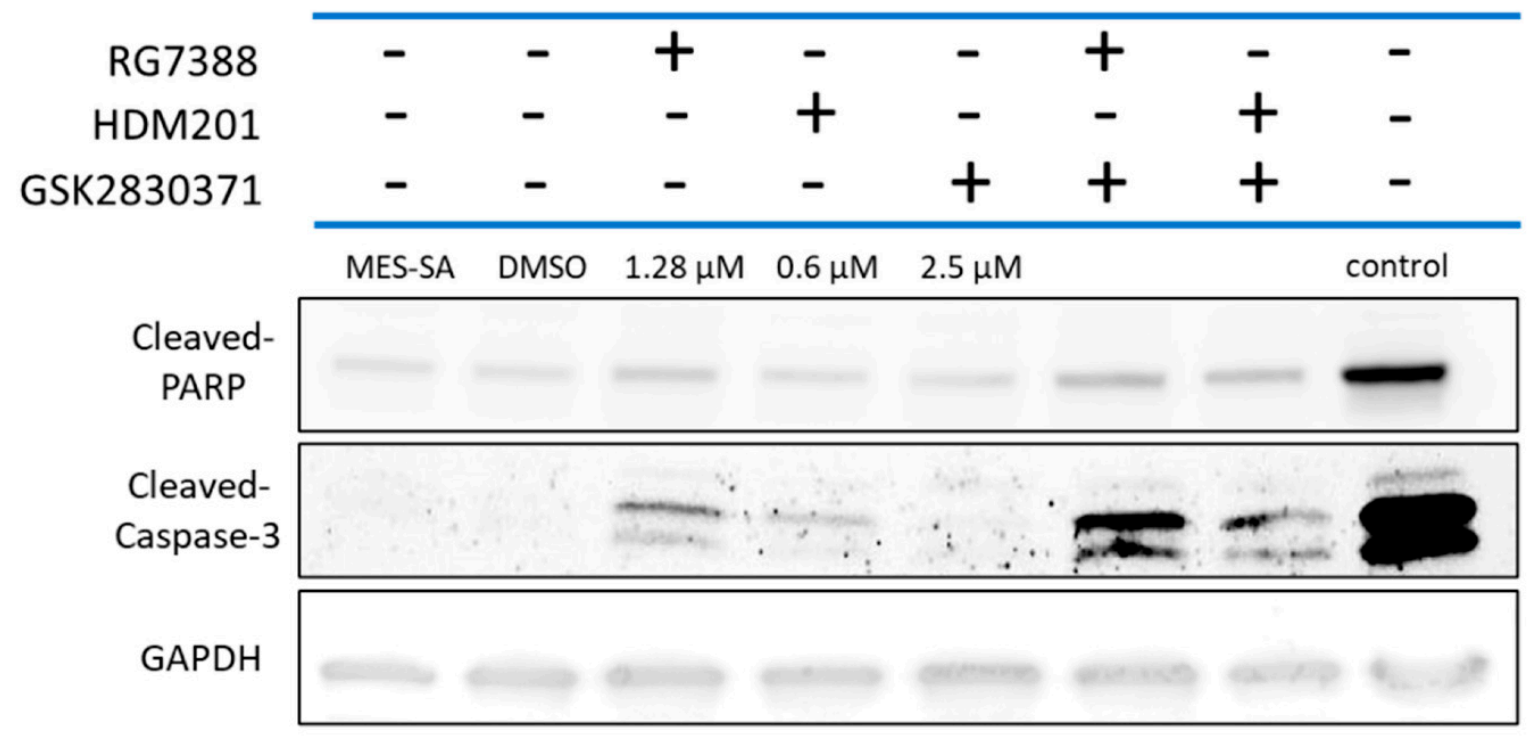

Figure 8. (A) Caspase-3/7 catalytic activity in MES-SA cells following $24 \mathrm{~h}$ treatment with either RG7388, HDM201 or GSK2830371 as single agents and in combination. Data are expressed as the mean fold change relative to DMSO-treated control, calculated from three independent repeats. Statistical significance was evaluated by a one-way ANOVA with Tukey's post hoc test for multiple comparisons. **** $p \leq 0.0001$. (B) Western Immunoblot of MES-SA cells treated for $24 \mathrm{~h}$ with RG7388, HDM201 and GSK2830371. Positive control was SH5Y5Y cells collected 4 h post X-irradiation with 2 Gy (provided by A. Yagbassan). Doses of RG7388 and HDM201 represent $10 \times$ their GI $_{50}$ concentrations. All strips were from the same membranes, which were cut into three. The top strip was probed for cleaved-PARP, the middle GAPDH, and the bottom cleaved-caspase-3. (C) Densitometry. Values were corrected for background signal, normalised to GAPDH, and then fold change was expressed relative to untreated control. The positive control was not included in the densitometry plot.

3.8. BCL2 and MCL-1 Inhibitors in Combination with MDM2 Inhibitors Fail to Lower the Apoptotic Threshold Required to Tip p53 ${ }^{W T}$ Cells into Apoptosis

Since the WIP1 inhibitor experiments demonstrated that MES-SA could be induced to undergo caspase-3/7 dependent apoptosis, Venetoclax, a specific BCL2 inhibitor, and MIM1, a specific MCL-1 inhibitor, were used to investigate whether inhibiting MDM2, in combination with either BCL2 or MCL-1, would also promote apoptosis. The hypothesis being that the inhibition of either BCL2 or MCL-1, anti-apoptotic proteins, would lower the apoptotic threshold so that MES-SA cells would be pushed into apoptosis rather than growth arrest. MES-SA, SK-UT-1 and SK-LMS-1 were resistant to inhibition with single- 
agent Venetoclax up to $10 \mu \mathrm{M}$ (Figure 9A) and MIM1 up to $3 \mu \mathrm{M}$ (Figure 9B), as determined by SRB. MES-SA, SK-UT-1 and SK-LMS-1 displayed a similar response to Venetoclax, but the response to MIM1 varied; MES-SA was the most sensitive with SK-LMS-1 the least.

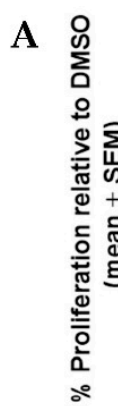

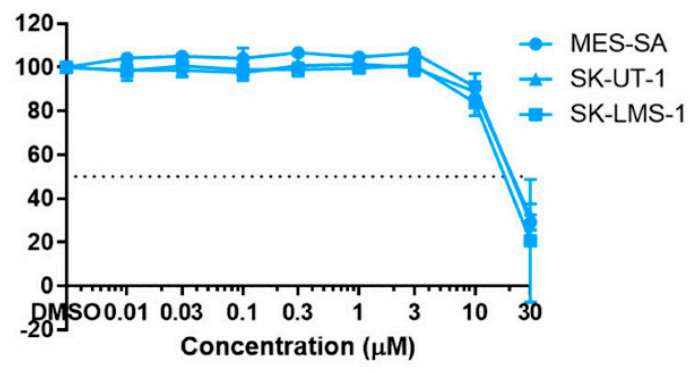
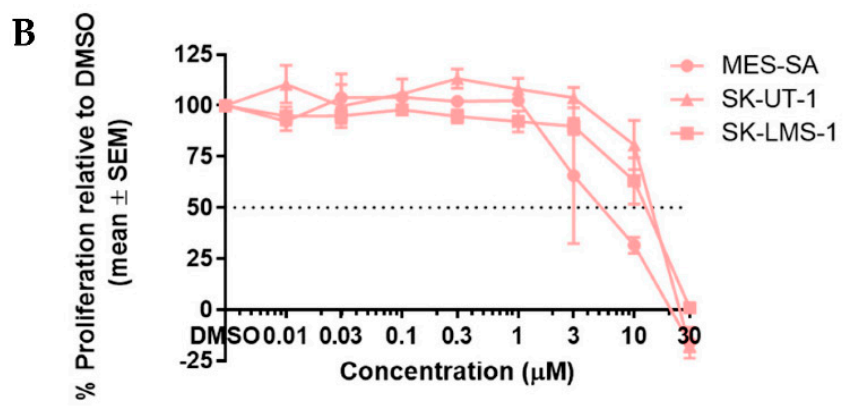

Figure 9. Growth inhibition curves for MES-SA, SK-UT-1 and SK-LMS-1 following incubation for 72 $\mathrm{h}$ with (A) Venetoclax; (B) MIM1 as determined by SRB. Data points represent mean \pm SEM of three independent repeats.

A dose-response matrix design was used to evaluate potential synergy for the combinations: RG7388 + Venetoclax (Figure 10A,B), HDM201 + Venetoclax (Figure 10C,D), RG7388 + MIM1 (Figure 10E,F) and HDM201 + MIM1 (Figure 10G,H). All four combinations resulted in an additive effect, with limited the overall evidence of synergy, using the ZIP model. Overall synergy scores ranged from -3 to +3 with peak synergy scores all still lower than 10 (Figure 10I).

A

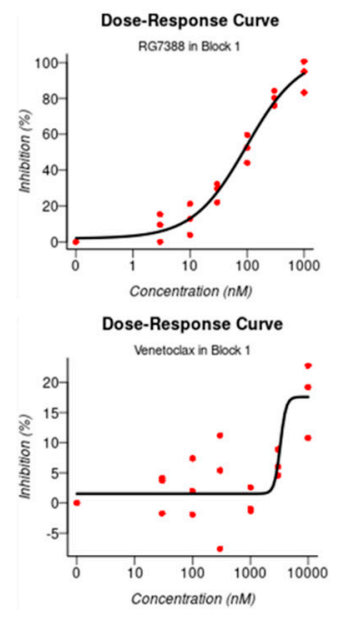

B

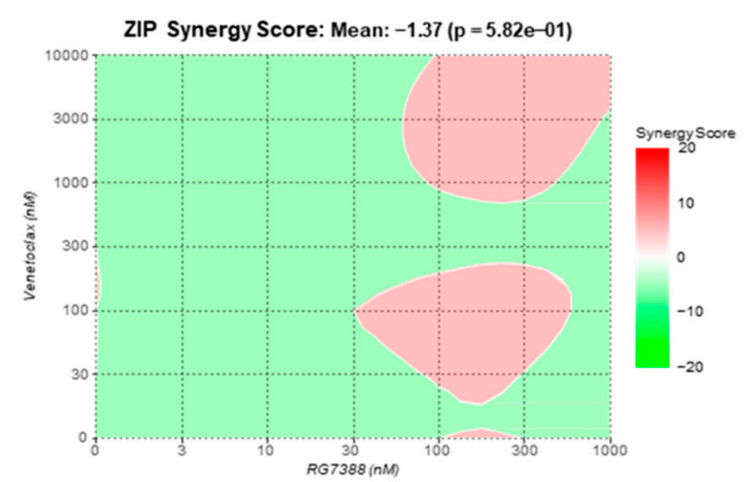

RG7388 \& Venetoclax

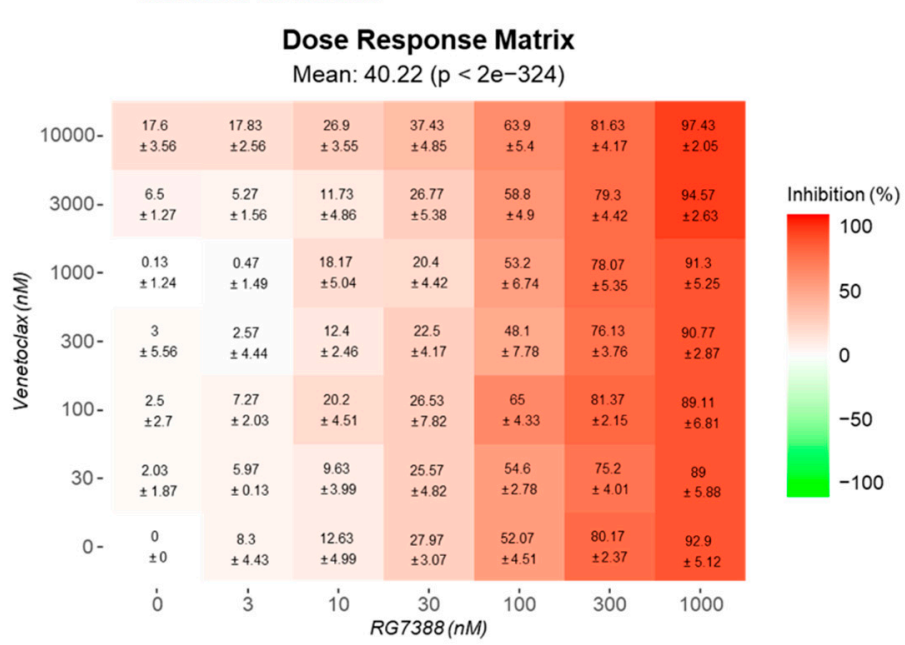

Figure 10. Cont.

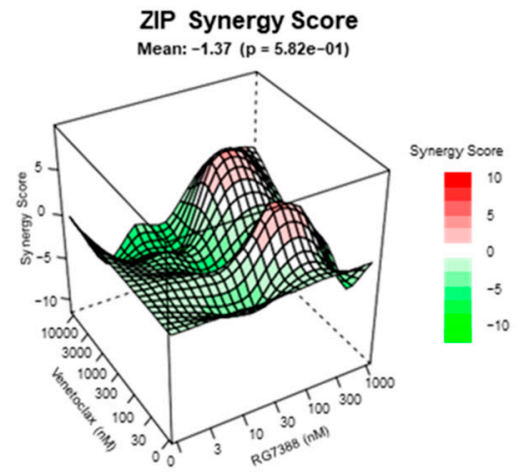


C

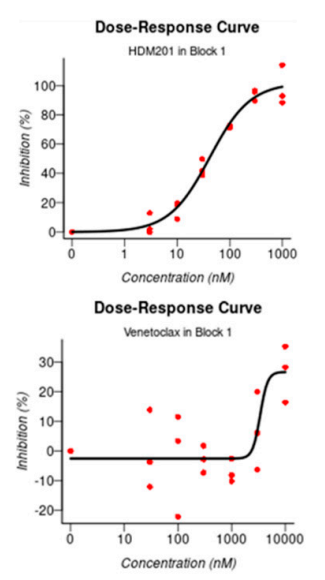

D

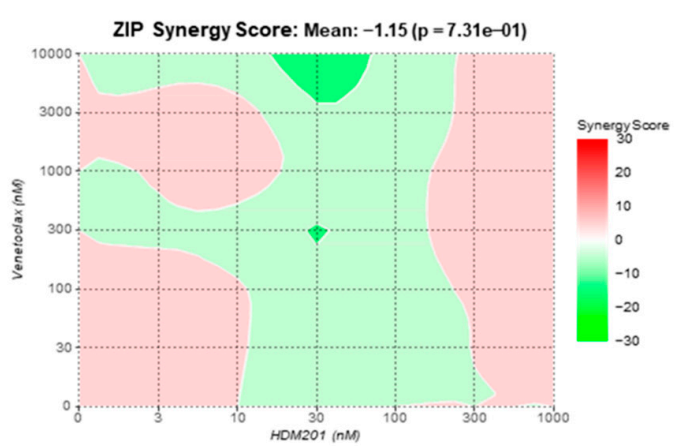

HDM201 \& Venetoclax
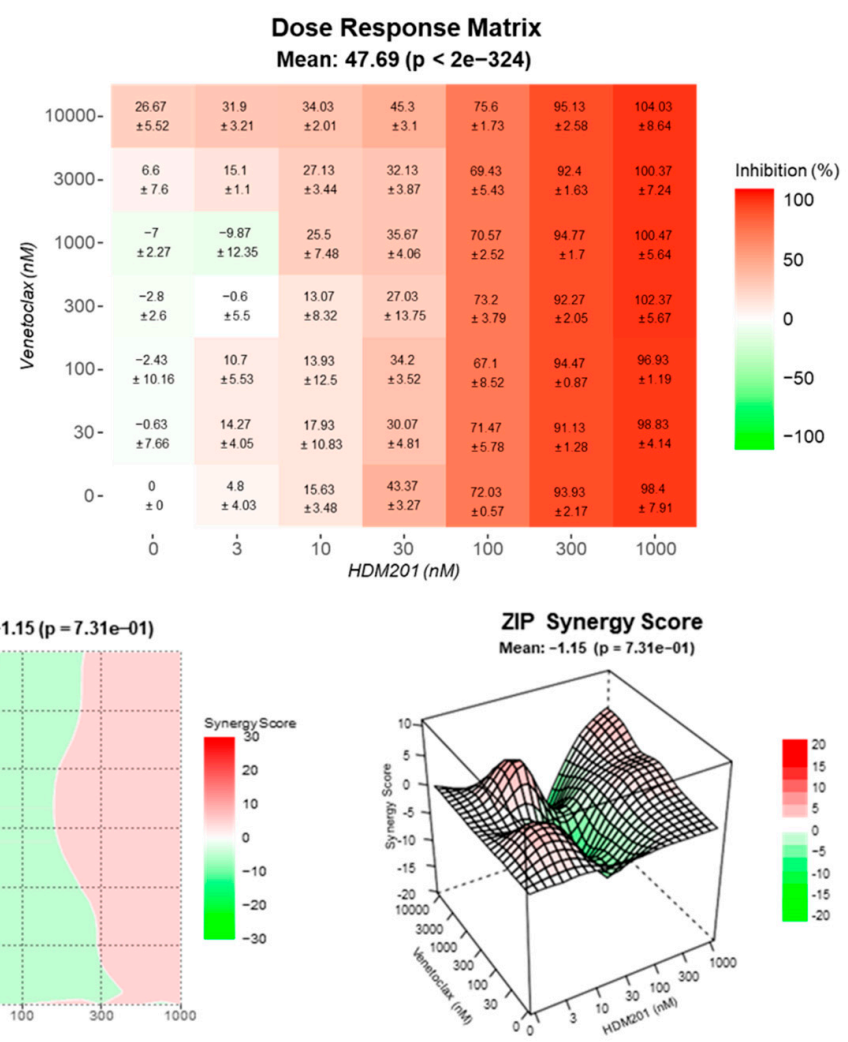

E

RG7388 \& MIM1
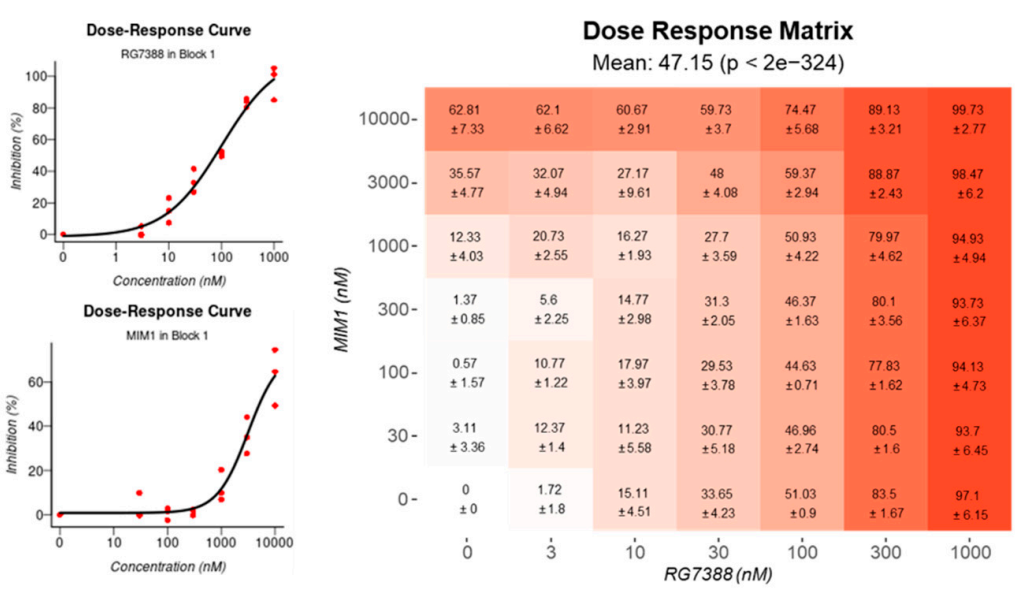

Inhibition (\%)

100

50

0

F
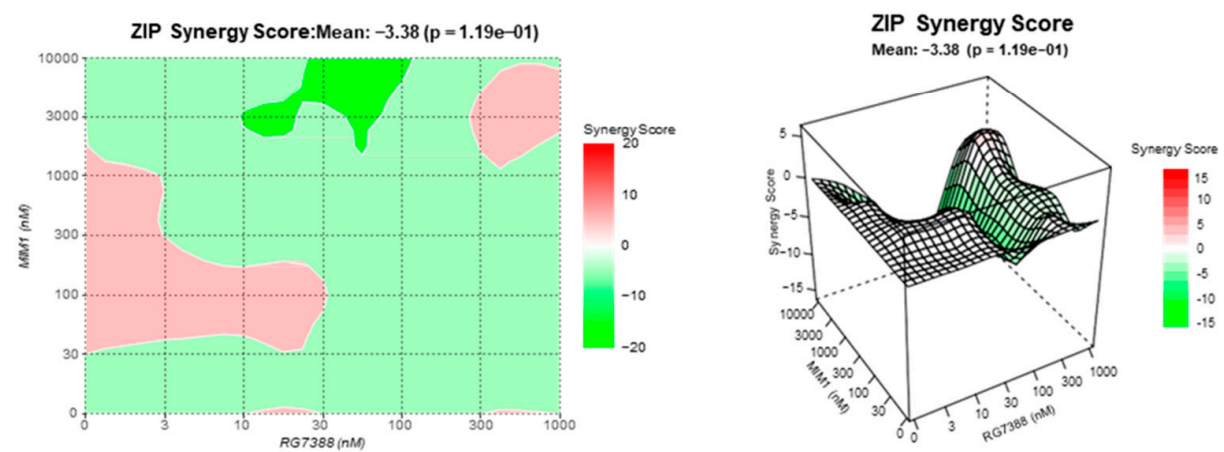

Figure 10. Cont. 
G

HDM201 \& MIM1

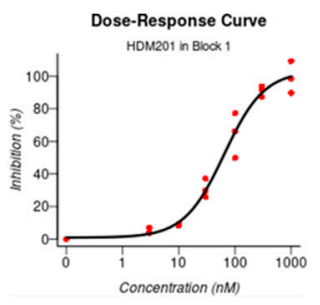

Dose-Response Curve
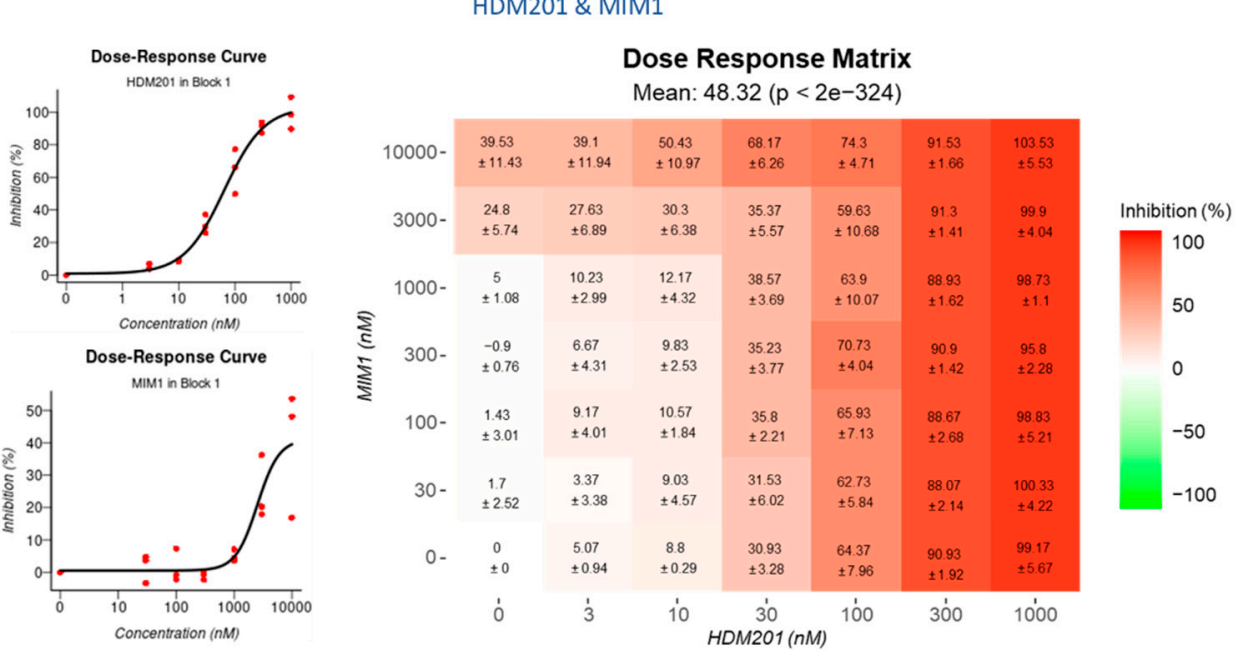

H

ZIP Synergy Score: Mean: $0.64(p=7.85 e-01)$
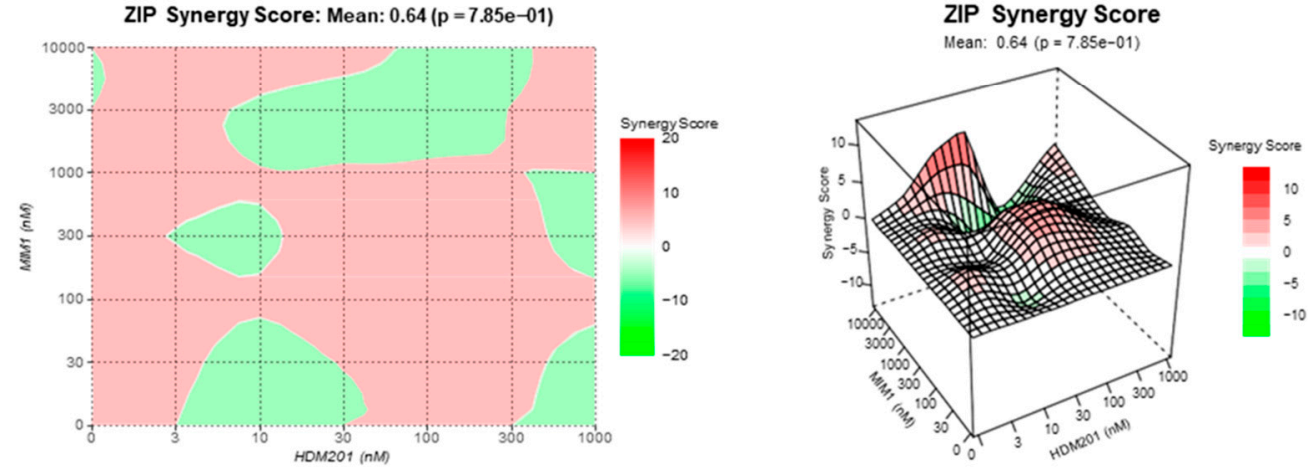

I

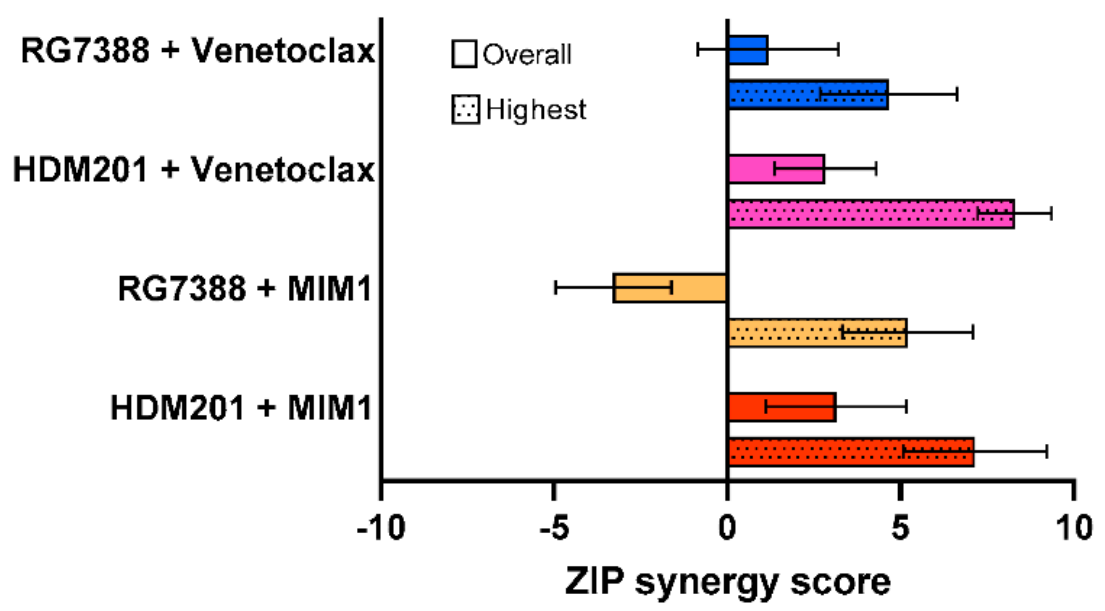

Figure 10. Dose-response curves for single agents, dose-response matrices (inhibition) and synergy maps generated using SynergyFinder for (A,B) Venetoclax and RG7388; (C,D) Venetoclax and HDM201; (E,F) MIM1 and RG7388; and (G,H) MIM1 and HDM201. On the synergy maps the areas with the greatest synergy are marked with a square; (I) Summary plot displaying the overall and highest synergy scores for each combination as determined by the Zero Interaction Potency (ZIP) Model. MES-SA cells were treated for $72 \mathrm{~h}$ and growth inhibition was assessed using the SRB assay. Results were then analysed using SynergyFinder. Data represent three independent repeats with mean \pm SEM. 
Even though the combination treatment failed to induce synergy, the levels of caspases 3 and 7 were assessed, as the main aim was to test the hypothesis that the inhibition of these anti-apoptotic proteins could tip the balance of pro-apoptotic and anti-apoptotic signals to induce apoptosis. MES-SA cells were treated for $24 \mathrm{~h}$ with either single-agent MDM2 inhibitor at 1 or $4 \times \mathrm{GI}_{50}$ concentrations, single-agent BCL2 inhibitor, Venetoclax at 1 or $10 \mu \mathrm{M}$, or a combination of both (Figure 11A). Doses of 1 and $10 \mu \mathrm{M}$ were used for Venetoclax, as no $\mathrm{GI}_{50}$ value was obtained for Venetoclax as a single agent. There was little to no increase detected in the levels of caspase 3 or 7 , with the only statistically significant difference noted between RG7388 and RG7388 $\left(4 \times \mathrm{GI}_{50}\right)+$ Venetoclax $(10 \mu \mathrm{M})$, $p=0.0143$. However, even though statistically significant $(p=0.0143)$, the fold increase was less than 1.5.

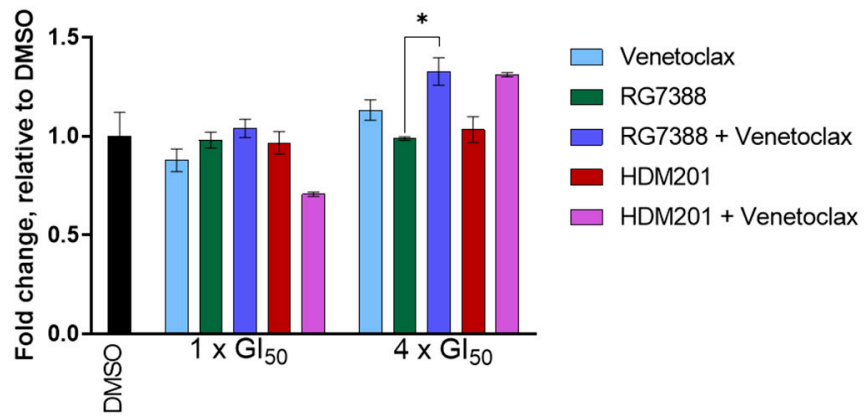

A

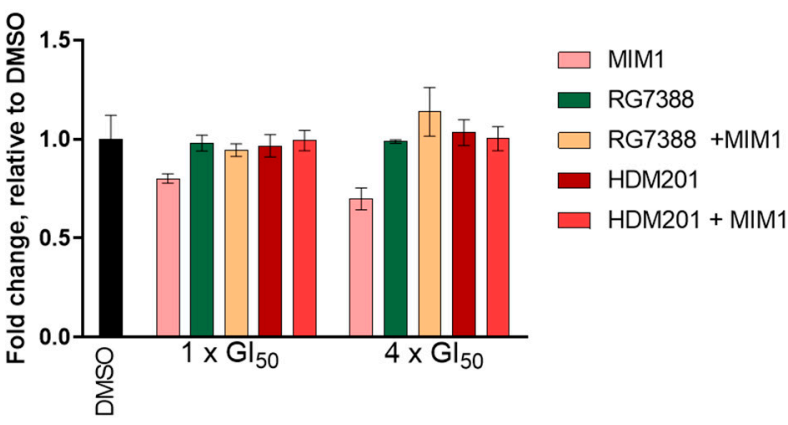

B

Figure 11. Caspase-3/7 catalytic activity in MES-SA cells following $24 \mathrm{~h}$ treatment with (A) Venetoclax and or RG7388/HDM201; (B) MIM1 and or RG7388/HDM201, assessed by Caspase-Glo 3/7 assay. Data are presented as the mean fold change relative to DMSO control, calculated from three independent repeats. Statistical significance was evaluated by one-way ANOVA with Tukey's post hoc test for multiple comparisons, ${ }^{*} p \leq 0.05$.

It was further hypothesised that MDM2 inhibition, in combination with MCL-1 inhibition, would lower the apoptotic threshold in MES-SA and drive the cells into apoptosis. However, this was not supported by the results presented in Figure 11B. When MES-SA cells were treated with either single-agent MDM2 inhibitors at 1 or $4 \times \mathrm{GI}_{50}$ concentrations, single agent MCL-1 inhibitor, MIM1 at 1 or $10 \mu \mathrm{M}$, or a combination of both, there was no statistically significant difference in fold change, relative to DMSO control for any comparison. Similar to Venetoclax, no $\mathrm{GI}_{50}$ value was calculated for MIM1 as a single agent at physiologically relevant doses; therefore, 1 and $10 \mu \mathrm{M}$ doses were used. Whilst Venetoclax and MIM1 may be able to induce apoptosis in other cell types, they were unable to do so with the uLMS cell lines.

\section{Discussion}

RG7388 and HDM201 are potent, selective antagonists of the MDM2-p53 interaction that can effectively stabilise and activate p53 in a dose-dependent manner. Following treatment with MDM2 inhibitors, two distinct responses can occur: either cell cycle arrest (quiescence or senescence) or apoptosis [10,11]. Following cellular stress, one of the main functions of activated p53 is to trigger cell-cycle arrest through the induction of the downstream transcriptional target $\mathrm{p} 21^{\mathrm{WAF} 1}$ (CDKN1A), which encodes a cyclin-dependent kinase inhibitor and arrests cells in the $G_{1}$ and $G_{2}$ phases [42]. It is thought that cell cycle arrest is prioritised over the induction of apoptosis as a means of protection; the priority is to stop the propagation of cells with damaged DNA, with apoptosis being the ultimate end point. Therefore, it was suggested that apoptosis could only occur under certain conditions that may be dependent on cell type, once a particular transcriptional threshold is achieved through either p53 reactivation or suppression of its negative regulators [43-46]. The main 
aim of this research was to identify targeted combination treatments capable of inducing apoptosis at lower threshold doses.

Whilst the overexpression of MDM2 was linked to chemoresistance, it was also reported that, in response to MDM2 inhibition, it is these cells that preferentially undergo apoptosis [47-52]. Genomic data profiled from 207 soft-tissue sarcoma patients revealed that the most common copy number alteration was the amplification of MDM2 that occurred in 56 (27.1\%) of the samples [53]; however, when considering just uterine sarcomas, MDM2 was only found to be amplified in 6/108 (5.6\%) and when narrowing this down further to specifically uLMS, in only $3 / 80$ (3.8\%) [54], suggesting that amplification of MDM2 in uLMS patients is not a common event. Therefore, MDM2 inhibitor treatment alone may not induce apoptosis in this subset of sarcoma patients, and might instead result in transient cell cycle arrest.

As well as MDM2, the PPM1D/WIP1 phosphatase has an additional negative auto regulatory effect on $\mathrm{p} 53$, by dephosphorylating the key amino acid residues required for its activation, and was implicated in resistance mechanisms to p53-dependent therapies. In the current research project, GSK2830371, a potent and selective WIP1 phosphatase inhibitor, displayed minimal growth inhibitory effects on LMS cell lines as a single agent at doses of up to $10 \mu \mathrm{M}$, irrespective of p53 status, consistent with previous reports across a wide range of PPM1D (WIP1) non-amplified and non-mutant cell lines [23,25,55]. However, Gilmartin et al. and Esfandiari et al. reported that, in cells with amplified PPM1D or activated by mutation, GSK2830371 inhibited cell growth with $\mathrm{IC}_{50}$ values $<4 \mu \mathrm{M}$, but not in WIP1-amplified p53 ${ }^{\mathrm{MUT}}$ cells (e.g., BT474) [21,23].

It was previously reported that GSK2830371 potentiated the effect of MDM2 inhibition in $\mathrm{p} 53^{\mathrm{WT}}$ cell line $[23,25,55]$; hence, it was hypothesised that GSK2830371 would also potentiate the effect of MDM2 inhibitors on $\mathrm{p} 53^{\mathrm{WT}} \mathrm{uLMS}$ cells. Consistent with previous results, GSK2830371 was shown to significantly potentiate the growth inhibitory effects of RG7388 and HDM201 at $2.5 \mu \mathrm{M}$ (Figure 3A-D), and significantly increase the mRNA expression of p53 transcriptional target genes (Figure 7A).

To confirm that the potentiation observed with either RG7388 or HDM201 and GSK2830371 was p53 dependent, p53 ${ }^{\text {MUT }}$ SK-UT-1 uLMS cells were also tested; unlike the p53 ${ }^{\text {WT }}$ MES-SA cells, no potentiation was observed following combination treatment (Figure $3 \mathrm{E}-\mathrm{H}$ ). Interestingly, there was a small but statistically significant increase in the expressions of some of the p53 transcriptional target genes; CDKN1A, MCL-1, NOXA and TP53INP1; although, all fold increases were less than 2, and as displayed in Figure 3E-H, were insufficient for affecting cell growth, confirming that the potentiation observed was p53 dependent. A similar finding was reported by Wu et al. in the p53 ${ }^{\mathrm{MUT}}$ WM35-R cutaneous melanoma cell line [25].

The cellular outcome of the response to signalling through the p53 network depends on the strength of upstream and auto-regulatory signals to p53 and the balance of downstream pro-apoptotic and anti-apoptotic proteins. Our results show that amplifying the signalling to $\mathrm{p} 53$, by inhibiting WIP1 phosphatase and enhancing p53 activation by MDM2 inhibitors, was more effective for pushing cells into apoptosis than inhibiting the antiapoptotic proteins BCL2 and MCL-1, which acted downstream of p53. As single agents, neither the MDM2 inhibitor nor GSK2830371 increased caspase 3/7 activity. However, there was a significant increase in caspase-3/7 activity (Figure 8A) following treatment with either MDM2 inhibitor in combination with GSK2830371, as well as an increase in both cleaved-PARP and cleaved-caspase-3 (Figure 8C), suggesting that MDM2 inhibitor treatment alone caused the insufficient activation of p53 and/or suppression of its negative regulators at the doses tested, triggering apoptosis in MES-SA uLMS cells. Figure 7 shows that, following combination treatment, there was a significant increase in the transcript levels of $C D K N 1 A$, indicative of increased p53 activation, coupled with a significant increase in the mRNA expression of pro-apoptotic genes-PUMA (previously shown to be pivotal in deciding cell fate in response to MDM2 inhibitors) FAS, NOXA and TP53INP1-indicating a sustained increase in the activation of p53 transcriptional activity consistent with the ob- 
served synergy and push of the cells into apoptosis [46]. Figure 4A shows that the increase in transcript levels of PUMA translated to an increase in protein levels following combination treatment. As BCL2 and MCL-1 are considered two of the main anti-apoptotic proteins, it was hypothesised that, by combining MDM2 inhibitors with either Venetoclax (BCL2 inhibitor) or MIM1 (MCL-1 inhibitor), the apoptotic threshold could be lowered, and thus cells would undergo apoptosis. However, this was not the case as, not only did all combinations result in at most an overall additive effect (Figure 10), but there was also no significant increase in caspase-3/7 activity (Figure 11A,B). The only exception to this was for RG7388 $\left(4 \times \mathrm{GI}_{50}\right)$ compared to RG7388 $\left(4 \times \mathrm{GI}_{50}\right)+$ Venetoclax $(10 \mu \mathrm{M})$. These results are in contrast to Mukherjee et al., who showed that cell death was achieved via apoptosis in a range of melanoma cell lines by combining Venetoclax and S63845 (MCL-1 inhibitor) [56]. The dual targeting of BCL2 (Venetoclax) and MCL-1 (S63845) was also suggested as an effective treatment for patients with myeloma, as both had little effect as single agents but, in combination at low doses, they were able to significantly increase levels of apoptosis. This was also demonstrated for a primary sample taken from a Venetoclax resistant patient. Mechanistically, the combination induced apoptosis in a BAX/BAK-dependent manner, with $B C L X_{L}$ as the major resisting factor [57]. From the studies mentioned above, a triple combination of MDM2 inhibitor with Venetoclax and MIM1 would be worth exploring.

The failures of RG7388 and HDM201 as single agents to induce apoptosis was not due to an inability to stabilise p53 and activate downstream transcriptional targets; therefore, further research is warranted, both to elucidate the mechanistic reasons as to why, and to also explore other avenues. As of now, apart from p53 status, there are no putative biomarkers of response to MDM2 inhibitors. Jeay et al. [58] suggested gene signatures; however, these were later found to be unreliable when taking into consideration cell lines harbouring alterations that inactivated p53 [59]. Clearly, more research is needed to find reliable biomarkers which can be used as predictors of response for both MDM2 and WIP1 inhibitors.

\section{Conclusions}

WIP1 (PPM1D) has a significant anti-apoptotic effect on uLMS, whereas BCL2 or MCL-1 appear to play little or no role in this cancer cell type. Therefore, this research presents the possibility of a combination treatment with MDM2 and WIP1 inhibitors as a potential treatment option for $\mathrm{p} 53^{\mathrm{WT}} \mathrm{uLMS}$ that warrants further investigation and the further development of WIP1 inhibitors suitable for in vivo and clinical evaluation.

Supplementary Materials: The following are available online at https:/ / www.mdpi.com/article/10 .3390/cancers14010014/s1, Figure S1: Original western blots for Figure 4, Figure S2: Original western blots for Figure 8.

Author Contributions: Conceptualization, V.C., Y.D. and J.L.; methodology, V.C., Y.D. and J.L.; formal analysis, V.C.; writing-original draft preparation, V.C.; writing-review and editing, V.C., Y.D. and J.L.; supervision, Y.D. and J.L.; funding acquisition, Y.D. and J.L. All authors have read and agreed to the published version of the manuscript.

Funding: This research was funded in memory of Nicky Asbury by Friends of Nicky Asbury/Faculty of Medical Sciences/Newcastle University Alumni, grant number C0190N3041, and Sarcoma UK, grant number SUK201.2017.

Institutional Review Board Statement: Not applicable.

Informed Consent Statement: Not applicable.

Data Availability Statement: The data presented in this study are available on request from the corresponding authors.

Conflicts of Interest: The authors declare no conflict of interest. 


\section{Appendix A}

Table A1. Details of antibodies used for Western immunoblotting. BSA, Bovine serum albumin.

\begin{tabular}{ccccccc}
\hline Protein & Product & Source & Company & Dilution & Diluent \\
\hline GAPDH & $(14 C 10) \# 2118$ & Rabbit & Cell Signalling Technologies & $1: 1000$ & Milk \\
\hline PARP-1 & $($ C2-10) \#4338-MC & Mouse & Trevigen & $1: 1000$ & Milk \\
\hline Cleaved-PARP & (Asp 214) \#9541 & Rabbit & Cell Signalling Technologies & $1: 1000$ & Milk \\
\hline MDM2 & OP46 & Mouse & EMD Millipore Corporation & $1: 300$ & Milk \\
\hline WIP1 & (F-10) sc-376257 & Mouse & Santa Cruz & $1: 1000$ & Milk \\
\hline p53 & (DO-1) sc-126 & Mouse & Santa Cruz & $1: 500$ & Milk \\
\hline pp53 & (E9Y4U) \#82530 & Rabbit & Cell Signalling Technologies & $1: 1000$ & BSA \\
\hline p21 & (EA10) OP64 & Mouse & EMD Millipore Corporation & $1: 100$ & Milk \\
\hline PUMA & (D30C10) \#12450 & Rabbit & Cell Signalling Technologies & $1: 1000$ & BSA \\
\hline Cleaved-caspase-3 & (Asp175) (5A1E) \#9664 & Rabbit & Cell Signalling Technologies & $1: 1000$ & Milk \\
\hline
\end{tabular}

Table A2. Details of primers used for qRT-PCR.

\begin{tabular}{|c|c|}
\hline Gene Name & Primer Sequence \\
\hline GAPDH & $\begin{array}{l}\text { F-5'-CAATGACCCCTTCATTGACC-3' } \\
\text { R-5'-GATCTCGCTCCTGGAAGAT-3' }\end{array}$ \\
\hline$M C L-1$ & $\begin{array}{l}\text { F-5'-GTGCCTTTGTGGCTAAACACT-3' } \\
\text { R-5'-AGTCCCGTTTTGTCCTTACGA-3' }\end{array}$ \\
\hline$B C L 2$ & $\begin{array}{c}\text { F-5'-GGTGGGGTCATGTGTGTGG-3' } \\
\text { R-5'-CGGTTCAGGTACTCAGTCATCC-3' }\end{array}$ \\
\hline TP53 & $\begin{array}{l}\text { F-5'-CAGCACATGACGGAGGTTGT-3' } \\
\text { R-5'-TCATCCAAATACTCCACACGC-3' }\end{array}$ \\
\hline$P 21$ & $\begin{array}{c}\text { F-5'-TGTCCGTCAGAACCCATGC-3' } \\
\text { R-5'-AAAGTCGAAGTTCCATCGCTC-3' }\end{array}$ \\
\hline MDM2 & $\begin{array}{l}\text { F-5'-AGTAGCAGTGAATCTACAGGGA-3' } \\
\text { R-5'-CTGATCCAACCAATCACCTGAAT-3' }\end{array}$ \\
\hline PUMA & $\begin{array}{l}\text { F-5'-ACCTCAACGCACAGTACGA-3' } \\
\text { R-5'-CTGGGTAAGGGCAGGAGTC-3' }\end{array}$ \\
\hline FAS & $\begin{array}{c}\text { F-5'-AGATTGTGTGATGAAGGACATGG-3' } \\
\text { R-5'-TGTTGCTGGTGAGTGTGCATT-3' }\end{array}$ \\
\hline NOXA & $\begin{array}{c}\text { F-5'-TGCTACACAATGTGGCGTC-3' } \\
\text { R-5'-ACTTGGACATGGCCTCCCTTA-3' }\end{array}$ \\
\hline BCL2L11 & $\begin{array}{l}\text { F-5'-TAAGTTCTGAGTGTGACCGAGA-3' } \\
\text { R-5'-GCTCTGTCTGTAGGGAGGTAGG-3' }\end{array}$ \\
\hline TP53INP1 & $\begin{array}{l}\text { F-5'-TCTTGAGTGCTTGGCTGATACA-3' } \\
\text { R-5'-GGTGGGGTGATAAACCAGCTC-3' }\end{array}$ \\
\hline$B I D$ & $\begin{array}{l}\text { F-5'-ATGGACCGTAGCATCCCTCC-3' } \\
\text { R-5'-GTAGGTGCGTAGGTTCTGGT-3' }\end{array}$ \\
\hline$B A X$ & $\begin{array}{l}\text { F-5'-CCCGAGAGGTCTTTTTCCGAG-3' } \\
\text { R-5'-CCAGCCCATGATGGTTCTGAT-3' }\end{array}$ \\
\hline PPM1D & $\begin{array}{l}\text { F-5'-TTGTCAGAGCTGTGGAGGTG-3' } \\
\text { R-5'-AGTGAGTCGAGGTCGTTTCC-3 }\end{array}$ \\
\hline
\end{tabular}


Table A3. All statistically significant fold changes in mRNA expression of selective p53 transcriptional targets, as determined by a two-way ANOVA with Tukey's post hoc test for multiple comparisons between MES-SA cells when treated with RG7388/HDM201 inhibitors and GSK2830371 as single agents or in combination for $6 \mathrm{~h}$.

\begin{tabular}{|c|c|c|}
\hline MES-SA & Treatment & $p$-Value \\
\hline \multirow[t]{15}{*}{ CDKN1A } & DMSO vs. $2.5 \mu \mathrm{M}$ GSK2830371 & $<0.0001$ \\
\hline & DMSO vs. $1 \mu \mathrm{M}$ RG7388 & $<0.0001$ \\
\hline & DMSO vs. $1 \mu \mathrm{M}$ HDM201 & $<0.0001$ \\
\hline & DMSO vs. $1 \mu \mathrm{M}$ HDM201 + $2.5 \mu \mathrm{M}$ GSK2830371 & $<0.0001$ \\
\hline & 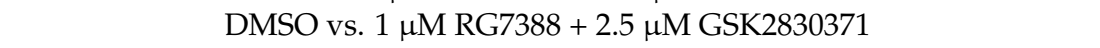 & $<0.0001$ \\
\hline & $2.5 \mu \mathrm{M}$ GSK2830371 vs. $1 \mu \mathrm{M}$ RG7388 & $<0.0001$ \\
\hline & $2.5 \mu \mathrm{M}$ GSK 2830371 vs. $1 \mu \mathrm{M}$ HDM201 & $<0.0001$ \\
\hline & $2.5 \mu \mathrm{M}$ GSK2830371 vs. 1 M HDM201 + $2.5 \mu \mathrm{M}$ GSK2830371 & $<0.0001$ \\
\hline & $2.5 \mu \mathrm{M}$ GSK 2830371 vs. $1 \mu \mathrm{M}$ RG7388 + $2.5 \mu \mathrm{M}$ GSK2830371 & $<0.0001$ \\
\hline & $1 \mu \mathrm{M}$ RG7388 vs. $1 \mu \mathrm{M}$ HDM201 & $<0.0001$ \\
\hline & $1 \mu \mathrm{M}$ RG7388 vs. $1 \mu \mathrm{M}$ HDM201 + $2.5 \mu \mathrm{M}$ GSK2830371 & $<0.0001$ \\
\hline & $1 \mu \mathrm{M}$ RG7388 vs. $1 \mu \mathrm{M}$ RG7388 + 2.5 нM GSK2830371 & $<0.0001$ \\
\hline & $1 \mu \mathrm{M}$ HDM201 vs. $1 \mu \mathrm{M}$ HDM201 + $2.5 \mu \mathrm{M}$ GSK2830371 & $<0.0001$ \\
\hline & $1 \mu \mathrm{M}$ HDM201 vs. $1 \mu \mathrm{M}$ RG7388 + 2.5 нM GSK2830371 & $<0.0001$ \\
\hline & $1 \mu \mathrm{M}$ HDM201 + $2.5 \mu \mathrm{M}$ GSK2830371 vs. $1 \mu \mathrm{M}$ RG7388 + $2.5 \mu \mathrm{M}$ GSK2830371 & $<0.0001$ \\
\hline \multirow[t]{14}{*}{ MDM2 } & DMSO vs. $2.5 \mu \mathrm{M}$ GSK2830371 & 0.0088 \\
\hline & DMSO vs. $1 \mu \mathrm{M}$ RG7388 & $<0.0001$ \\
\hline & DMSO vs. $1 \mu \mathrm{M}$ HDM201 & $<0.0001$ \\
\hline & DMSO vs. $1 \mu \mathrm{M}$ HDM201 + 2.5 M GSK2830371 & $<0.0001$ \\
\hline & DMSO vs. $1 \mu \mathrm{M}$ RG7388 + $2.5 \mu \mathrm{M}$ GSK2830371 & $<0.0001$ \\
\hline & $2.5 \mu \mathrm{M}$ GSK2830371 vs. $1 \mu \mathrm{M}$ RG7388 & $<0.0001$ \\
\hline & $2.5 \mu \mathrm{M}$ GSK2830371 vs. $1 \mu \mathrm{M}$ HDM201 & $<0.0001$ \\
\hline & 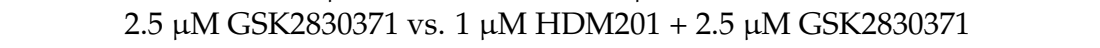 & $<0.0001$ \\
\hline & $2.5 \mu \mathrm{M}$ GSK2830371 vs. $1 \mu \mathrm{M}$ RG7388 + $2.5 \mu \mathrm{M}$ GSK2830371 & $<0.0001$ \\
\hline & $1 \mu \mathrm{M}$ RG7388 vs. $1 \mu \mathrm{M}$ HDM201 & $<0.0001$ \\
\hline & $1 \mu \mathrm{M}$ RG7388 vs. $1 \mu \mathrm{M}$ HDM201 + $2.5 \mu \mathrm{M}$ GSK2830371 & $<0.0001$ \\
\hline & $1 \mu \mathrm{M}$ RG7388 vs. $1 \mu \mathrm{M}$ RG7388 + 2.5 нM GSK2830371 & $<0.0001$ \\
\hline & $1 \mu \mathrm{M}$ HDM201 vs. $1 \mu \mathrm{M}$ HDM201 + 2.5 нM GSK2830371 & $<0.0001$ \\
\hline & 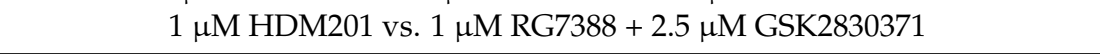 & $<0.0001$ \\
\hline$M C L-1$ & 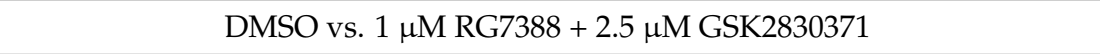 & 0.0060 \\
\hline \multirow[t]{11}{*}{ PUMA } & DMSO vs. $1 \mu$ M RG7388 & $<0.0001$ \\
\hline & DMSO vs. $1 \mu \mathrm{M}$ HDM201 & $<0.0001$ \\
\hline & DMSO vs. $1 \mu \mathrm{M}$ HDM201 + 2.5 M GSK2830371 & $<0.0001$ \\
\hline & 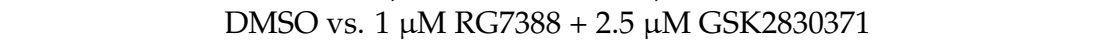 & $<0.0001$ \\
\hline & $2.5 \mu \mathrm{M}$ GSK2830371 vs. $1 \mu \mathrm{M}$ RG7388 & $<0.0001$ \\
\hline & $2.5 \mu \mathrm{M}$ GSK2830371 vs. $1 \mu \mathrm{M}$ HDM201 & $<0.0001$ \\
\hline & $2.5 \mu \mathrm{M}$ GSK2830371 vs. 1 M HDM201 + $2.5 \mu \mathrm{M}$ GSK2830371 & $<0.0001$ \\
\hline & $2.5 \mu \mathrm{M}$ GSK2830371 vs. $1 \mu \mathrm{M}$ RG7388 + 2.5 нM GSK2830371 & $<0.0001$ \\
\hline & 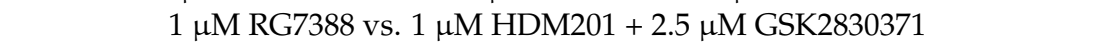 & 0.0008 \\
\hline & 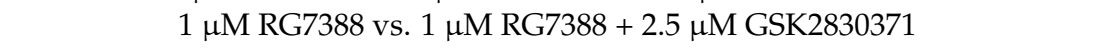 & $<0.0001$ \\
\hline & $1 \mu \mathrm{M}$ HDM201 vs. $1 \mu \mathrm{M}$ RG7388 + $2.5 \mu \mathrm{M}$ GSK2830371 & 0.0018 \\
\hline \multirow[t]{14}{*}{ FAS } & DMSO vs. $2.5 \mu \mathrm{M}$ GSK2830371 & $<0.0001$ \\
\hline & DMSO vs. $1 \mu \mathrm{M}$ RG7388 & $<0.0001$ \\
\hline & DMSO vs. $1 \mu \mathrm{M}$ HDM201 & $<0.0001$ \\
\hline & DMSO vs. $1 \mu \mathrm{M}$ HDM201 + 2.5 нM GSK2830371 & $<0.0001$ \\
\hline & DMSO vs. $1 \mu \mathrm{M}$ RG7388 + $2.5 \mu \mathrm{M}$ GSK2830371 & $<0.0001$ \\
\hline & $2.5 \mu \mathrm{M}$ GSK2830371 vs. $1 \mu \mathrm{M}$ RG7388 & $<0.0001$ \\
\hline & $2.5 \mu \mathrm{M}$ GSK2830371 vs. $1 \mu \mathrm{M}$ HDM201 & $<0.0001$ \\
\hline & 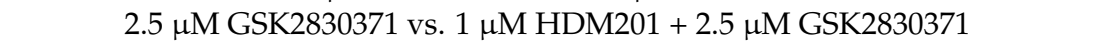 & $<0.0001$ \\
\hline & 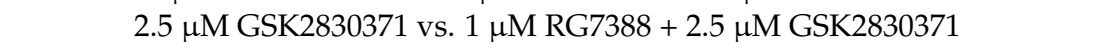 & $<0.0001$ \\
\hline & 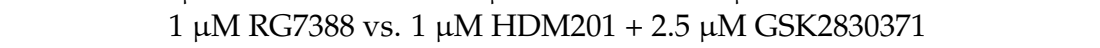 & $<0.0001$ \\
\hline & $1 \mu \mathrm{M}$ RG7388 vs. $1 \mu \mathrm{M}$ RG7388 + 2.5 M GSK2830371 & $<0.0001$ \\
\hline & $1 \mu \mathrm{M}$ HDM201 vs. $1 \mu \mathrm{M}$ HDM201 + 2.5 нM GSK2830371 & $<0.0001$ \\
\hline & $1 \mu \mathrm{M}$ HDM201 vs. $1 \mu \mathrm{M}$ RG7388 + 2.5 нM GSK2830371 & $<0.0001$ \\
\hline & $1 \mu \mathrm{M}$ HDM $201+2.5 \mu \mathrm{M}$ GSK2830371 vs. $1 \mu \mathrm{M}$ RG7388 + $2.5 \mu \mathrm{M}$ GSK2830371 & $<0.0001$ \\
\hline
\end{tabular}


Table A3. Cont.

\begin{tabular}{|c|c|c|}
\hline MES-SA & Treatment & $p$-Value \\
\hline \multirow[t]{12}{*}{ NOXA } & DMSO vs. $2.5 \mu \mathrm{M}$ GSK2830371 & $<0.0001$ \\
\hline & DMSO vs. $1 \mu \mathrm{M}$ RG7388 & $<0.0001$ \\
\hline & DMSO vs. $1 \mu \mathrm{M}$ HDM201 & $<0.0001$ \\
\hline & DMSO vs. $1 \mu \mathrm{M}$ HDM $201+2.5 \mu \mathrm{M}$ GSK2830371 & $<0.0001$ \\
\hline & DMSO vs. $1 \mu \mathrm{M}$ RG7388 + $2.5 \mu \mathrm{M}$ GSK2830371 & $<0.0001$ \\
\hline & $2.5 \mu \mathrm{M}$ GSK2830371 vs. $1 \mu \mathrm{M}$ HDM201 + $2.5 \mu \mathrm{M}$ GSK2830371 & $<0.0001$ \\
\hline & $2.5 \mu \mathrm{M}$ GSK2830371 vs. $1 \mu \mathrm{M}$ RG7388 + $2.5 \mu \mathrm{M}$ GSK2830371 & $<0.0001$ \\
\hline & 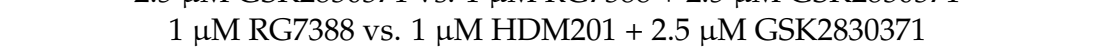 & $<0.0001$ \\
\hline & $1 \mu \mathrm{M}$ RG7388 vs. $1 \mu \mathrm{M}$ RG7388 + $2.5 \mu \mathrm{M}$ GSK2830371 & 0.0001 \\
\hline & $1 \mu \mathrm{M}$ HDM201 vs. $1 \mu \mathrm{M}$ HDM201 + $2.5 \mu \mathrm{M}$ GSK2830371 & $<0.0001$ \\
\hline & $1 \mu \mathrm{M}$ HDM201 vs. $1 \mu \mathrm{M}$ RG7388 + $2.5 \mu \mathrm{M}$ GSK2830371 & $<0.0001$ \\
\hline & $1 \mu \mathrm{M}$ HDM201 + $2.5 \mu \mathrm{M}$ GSK2830371 vs. $1 \mu \mathrm{M}$ RG7388 + $2.5 \mu \mathrm{M}$ GSK2830371 & $<0.0001$ \\
\hline \multirow[t]{13}{*}{ TP53INP1 } & DMSO vs. $2.5 \mu$ M GSK2830371 & $<0.0001$ \\
\hline & DMSO vs. $1 \mu \mathrm{M}$ RG7388 & $<0.0001$ \\
\hline & DMSO vs. $1 \mu \mathrm{M}$ HDM201 & $<0.0001$ \\
\hline & DMSO vs. $1 \mu \mathrm{M}$ HDM201 + $2.5 \mu \mathrm{M}$ GSK2830371 & $<0.0001$ \\
\hline & DMSO vs. $1 \mu \mathrm{M}$ RG7388 + $2.5 \mu \mathrm{M}$ GSK2830371 & $<0.0001$ \\
\hline & $2.5 \mu \mathrm{M}$ GSK 2830371 vs. $1 \mu \mathrm{M}$ HDM201 & $<0.0001$ \\
\hline & $2.5 \mu \mathrm{M}$ GSK2830371 vs. $1 \mu \mathrm{M}$ HDM201 + $2.5 \mu \mathrm{M}$ GSK2830371 & $<0.0001$ \\
\hline & $2.5 \mu \mathrm{M}$ GSK2830371 vs. $1 \mu \mathrm{M}$ RG7388 + $2.5 \mu \mathrm{M}$ GSK2830371 & $<0.0001$ \\
\hline & $1 \mu \mathrm{M}$ RG7388 vs. $1 \mu \mathrm{M}$ HDM201 & $<0.0001$ \\
\hline & $1 \mu \mathrm{M}$ RG7388 vs. $1 \mu \mathrm{M}$ HDM201 + $2.5 \mu \mathrm{M}$ GSK2830371 & $<0.0001$ \\
\hline & $1 \mu \mathrm{M}$ RG7388 vs. $1 \mu \mathrm{M}$ RG7388 + $2.5 \mu \mathrm{M}$ GSK2830371 & $<0.0001$ \\
\hline & $1 \mu \mathrm{M}$ HDM201 vs. $1 \mu \mathrm{M}$ HDM201 + $2.5 \mu \mathrm{M}$ GSK2830371 & $<0.0001$ \\
\hline & 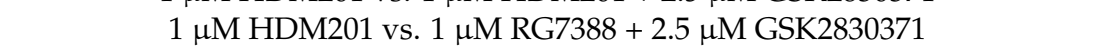 & $<0.0001$ \\
\hline \multirow[t]{4}{*}{$B I D$} & DMSO vs. $2.5 \mu \mathrm{M}$ GSK2830371 & 0.0242 \\
\hline & DMSO vs. $1 \mu \mathrm{M}$ RG7388 & 0.0119 \\
\hline & DMSO vs. $1 \mu \mathrm{M}$ HDM201 + $2.5 \mu \mathrm{M}$ GSK2830371 & 0.0220 \\
\hline & DMSO vs. $1 \mu \mathrm{M}$ RG7388 + $2.5 \mu \mathrm{M}$ GSK2830371 & 0.0039 \\
\hline \multirow[t]{3}{*}{$B A X$} & DMSO vs. $1 \mu \mathrm{M}$ HDM201 & 0.0013 \\
\hline & DMSO vs. $1 \mu \mathrm{M}$ HDM201 + $2.5 \mu \mathrm{M}$ GSK2830371 & 0.0001 \\
\hline & 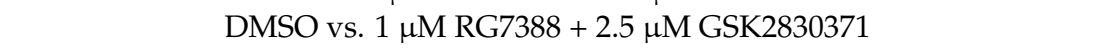 & 0.0002 \\
\hline \multirow[t]{9}{*}{ PPM1D } & DMSO vs. $1 \mu$ M RG7388 & $<0.0001$ \\
\hline & DMSO vs. $1 \mu \mathrm{M}$ HDM201 & $<0.0001$ \\
\hline & DMSO vs. $1 \mu \mathrm{M}$ HDM201 + $2.5 \mu \mathrm{M}$ GSK2830371 & 0.0020 \\
\hline & DMSO vs. $1 \mu \mathrm{M}$ RG7388 + $2.5 \mu \mathrm{M}$ GSK2830371 & $<0.0001$ \\
\hline & $2.5 \mu \mathrm{M}$ GSK 2830371 vs. $1 \mu \mathrm{M}$ RG7388 & 0.0002 \\
\hline & $2.5 \mu \mathrm{M}$ GSK2830371 vs. $1 \mu \mathrm{M}$ HDM201 & $<0.0001$ \\
\hline & $2.5 \mu \mathrm{M}$ GSK2830371 vs. $1 \mu \mathrm{M}$ HDM201 + $2.5 \mu \mathrm{M}$ GSK2830371 & 0.0088 \\
\hline & 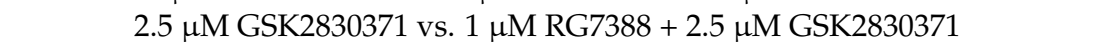 & $<0.0001$ \\
\hline & $1 \mu \mathrm{M}$ HDM201 vs. $1 \mu \mathrm{M}$ HDM201 + $2.5 \mu \mathrm{M}$ GSK2830371 & 0.0019 \\
\hline
\end{tabular}

Table A4. All statistically significant fold changes in mRNA expression of selective p53 transcriptional targets, as determined by a two-way ANOVA with Tukey's post hoc test for multiple comparisons between SK-UT-1 cells when treated with RG7388/HDM201 inhibitors and GSK2830371 as single agents or in combination for $6 \mathrm{~h}$.

\begin{tabular}{ccc}
\hline SK-UT-1 & Treatment & $p$-Value \\
\hline CDKN1A & $2.5 \mu \mathrm{M}$ GSK2830371 vs. $1 \mu \mathrm{M}$ RG7388 & 0.0005 \\
& $2.5 \mu \mathrm{M}$ GSK2830371 vs. $1 \mu \mathrm{M}$ HDM201 & 0.0022 \\
& $1 \mu \mathrm{M}$ RG7388 vs. 1 $\mu \mathrm{M}$ RG7388 + 2.5 $\mu \mathrm{M}$ GSK2830371 & 0.0114 \\
& $1 \mu \mathrm{M}$ HDM201 vs. $1 \mu \mathrm{M}$ RG7388 + 2.5 $\mu \mathrm{M}$ GSK2830371 & 0.0381 \\
\hline
\end{tabular}


Table A4. Cont.

\begin{tabular}{|c|c|c|}
\hline SK-UT-1 & Treatment & $p$-Value \\
\hline \multirow[t]{5}{*}{$M C L-1$} & DMSO vs. $1 \mu \mathrm{M}$ RG7388 & 0.0006 \\
\hline & $2.5 \mu \mathrm{M}$ GSK2830371 vs. 1 $\mu \mathrm{M}$ RG7388 & 0.0053 \\
\hline & $1 \mu \mathrm{M}$ RG7388 vs. $1 \mu \mathrm{M}$ HDM201 & 0.0085 \\
\hline & 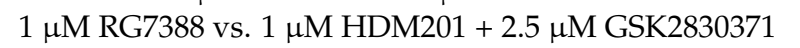 & $<0.0001$ \\
\hline & 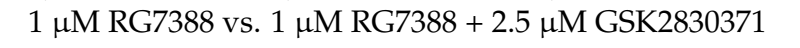 & 0.0300 \\
\hline \multirow[t]{7}{*}{ NOXA } & DMSO vs. $2.5 \mu \mathrm{M}$ GSK2830371 & $<0.0001$ \\
\hline & DMSO vs. $1 \mu \mathrm{M}$ HDM201 & $<0.0001$ \\
\hline & 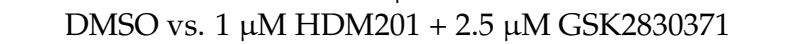 & 0.0280 \\
\hline & $2.5 \mu \mathrm{M}$ GSK2830371 vs. $1 \mu \mathrm{M}$ RG7388 & 0.0492 \\
\hline & $1 \mu \mathrm{M}$ RG7388 vs. $1 \mu \mathrm{M}$ HDM201 & 0.0017 \\
\hline & 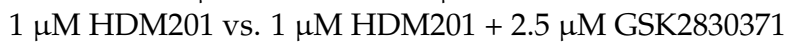 & 0.0228 \\
\hline & 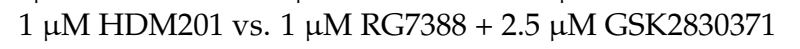 & 0.0024 \\
\hline \multirow[t]{2}{*}{$B C L 2 L 11$} & DMSO vs. $2.5 \mu \mathrm{M}$ GSK2830371 & 0.0462 \\
\hline & 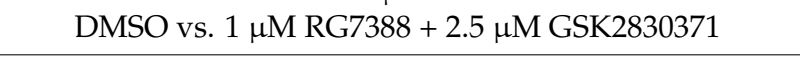 & 0.0136 \\
\hline \multirow[t]{4}{*}{ TP53INP1 } & DMSO vs. $1 \mu \mathrm{M}$ HDM201 & $<0.0001$ \\
\hline & 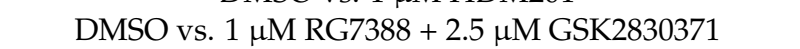 & 0.0014 \\
\hline & $1 \mu \mathrm{M}$ RG7388 vs. $1 \mu \mathrm{M}$ HDM201 & 0.0002 \\
\hline & 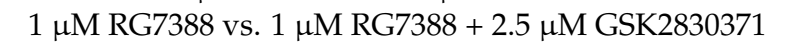 & 0.0058 \\
\hline$B A X$ & DMSO vs. $1 \mu \mathrm{M}$ HDM201 & 0.0453 \\
\hline
\end{tabular}

\section{References}

1. Zhao, Y.; Aguilar, A.; Bernard, D.; Wang, S. Small-Molecule Inhibitors of the MDM2-p53 Protein-Protein Interaction (MDM2 Inhibitors) in Clinical Trials for Cancer Treatment. J. Med. Chem. 2014, 58, 1038-1052. [CrossRef] [PubMed]

2. Vassilev, L.T.; Vu, B.T.; Graves, B.; Carvajal, D.; Podlaski, F.; Filipovic, Z.; Kong, N.; Kammlott, U.; Lukacs, C.; Klein, C.; et al. In Vivo Activation of the p53 Pathway by Small-Molecule Antagonists of MDM2. Science 2004, 303, 844-848. [CrossRef]

3. Ray-Coquard, I.; Blay, J.-Y.; Italiano, A.; Le Cesne, A.; Penel, N.; Zhi, J.; Heil, F.; Rueger, R.; Graves, B.; Ding, M.; et al. Effect of the MDM2 antagonist RG7112 on the P53 pathway in patients with MDM2-amplified, well-differentiated or dedifferentiated liposarcoma: An exploratory proof-of-mechanism study. Lancet Oncol. 2012, 13, 1133-1140. [CrossRef]

4. Levine, A.J. p53, the Cellular Gatekeeper for Growth and Division. Cell 1997, 88, 323-331. [CrossRef]

5. Kern, S.E.; Kinzler, K.W.; Bruskin, A.; Jarosz, D.; Friedman, P.; Prives, C.; Vogelstein, B. Identification of p53 as a Sequence-Specific DNA-Binding Protein. Science 1991, 252, 1708-1711. [CrossRef]

6. Pietenpol, J.A.; Tokino, T.; Thiagalingam, S.; El-Deiry, W.S.; Kinzler, K.W.; Vogelstein, B. Sequence-specific transcriptional activation is essential for growth suppression by p53. Proc. Natl. Acad. Sci. USA 1994, 91, 1998-2002. [CrossRef]

7. Rotter, V. p53, a transformation-related cellular-encoded protein, can be used as a biochemical marker for the detection of primary mouse tumor cells. Proc. Natl. Acad. Sci. USA 1983, 80, 2613-2617. [CrossRef]

8. Shi, D.; Gu, W. Dual Roles of MDM2 in the Regulation of p53: Ubiquitination Dependent and Ubiquitination Independent Mechanisms of MDM2 Repression of p53 Activity. Genes Cancer 2012, 3, 240-248. [CrossRef] [PubMed]

9. Lowe, S.W.; Cepero, E.; Evan, G. Intrinsic tumour suppression. Nat. Cell Biol. 2004, 432, 307-315. [CrossRef]

10. Xue, W.; Zender, L.; Miething, C.; Dickins, R.A.; Hernando, E.; Krizhanovsky, V.; Cordon-Cardo, C.; Lowe, S.W. Senescence and tumour clearance is triggered by p53 restoration in murine liver carcinomas. Nature 2007, 445, 656-660. [CrossRef] [PubMed]

11. Ventura, A.; Kirsch, D.G.; McLaughlin, M.E.; Tuveson, D.A.; Grimm, J.; Lintault, L.; Newman, J.; Reczek, E.E.; Weissleder, R.; Jacks, T. Restoration of p53 function leads to tumour regression in vivo. Nature 2007, 445, 661-665. [CrossRef]

12. Haupt, Y.; Maya, R.; Kazaz, A.; Oren, M. Mdm2 promotes the rapid degradation of p53. Nature 1997, 387, 296-299. [CrossRef] [PubMed]

13. Kubbutat, M.H.; Vousden, K.H. Proteolytic cleavage of human p53 by calpain: A potential regulator of protein stability. Mol. Cell. Biol. 1997, 17, 460-468. [CrossRef]

14. Moll, U.M.; Petrenko, O. The MDM2-p53 interaction. Mol. Cancer Res. 2003, 1, 1001-1008.

15. Michaelis, M.; Rothweiler, F.; Barth, S.; Cinatl, J.; Van Rikxoort, M.; Löschmann, N.; Voges, Y.; Breitling, R.; Von Deimling, A.; Rödel, F.; et al. Adaptation of cancer cells from different entities to the MDM2 inhibitor nutlin-3 results in the emergence of p53-mutated multi-drug-resistant cancer cells. Cell Death Dis. 2011, 2, e243. [CrossRef]

16. Ruark, E.; Snape, K.; Humburg, P.; Loveday, C.; Bajrami, I.; Brough, R.; Rodrigues, D.N.; Renwick, A.; Seal, S.; Ramsay, E.; et al. Mosaic PPM1D mutations are associated with predisposition to breast and ovarian cancer. Nature 2013, 493, 406-410. [CrossRef] [PubMed] 
17. Rauta, J.; Alarmo, E.-L.; Kauraniemi, P.; Karhu, R.; Kuukasjärvi, T.; Kallioniemi, A. The serine-threonine protein phosphatase PPM1D is frequently activated through amplification in aggressive primary breast tumours. Breast Cancer Res. Treat. 2005, 95, 257-263. [CrossRef]

18. Tan, D.S.P.; Lambros, M.B.K.; Rayter, S.; Natrajan, R.; Vatcheva, R.; Gao, Q.; Marchiò, C.; Geyer, F.C.; Savage, K.; Parry, S.; et al. PPM1D Is a Potential Therapeutic Target in Ovarian Clear Cell Carcinomas. Clin. Cancer Res. 2009, 15, 2269-2280. [CrossRef]

19. Lowe, J.; Cha, H.; Lee, M.O.; Mazur, S.J.; Appella, E.; Fornace, A.J., Jr. Regulation of the Wip1 phosphatase and its effects on the stress response. Front. Biosci. 2012, 17, 1480-1498. [CrossRef] [PubMed]

20. Choi, M.; Shi, J.; Jung, S.H.; Chen, X.; Cho, K.-H. Attractor Landscape Analysis Reveals Feedback Loops in the p53 Network That Control the Cellular Response to DNA Damage. Sci. Signal. 2012, 5, ra83. [CrossRef] [PubMed]

21. Gilmartin, A.G.; Faitg, T.H.; Richter, M.; Groy, A.; Seefeld, M.A.; Darcy, M.G.; Peng, X.; Federowicz, K.; Yang, J.; Zhang, S.-Y.; et al. Allosteric Wip1 phosphatase inhibition through flap-subdomain interaction. Nat. Chem. Biol. 2014, 10, 181-187. [CrossRef]

22. Pechackova, S.; Burdova, K.; Benada, J.; Kleiblova, P.; Jenikova, G.; Macurek, L. Inhibition of WIP1 phosphatase sensitizes breast cancer cells to genotoxic stress and to MDM2 antagonist nutlin-3. Oncotarget 2016, 7, 14458-14475. [CrossRef]

23. Esfandiari, A.; Hawthorne, T.A.; Nakjang, S.; Lunec, J. Chemical Inhibition of Wild-Type p53-Induced Phosphatase 1 (WIP1/PPM1D) by GSK2830371 Potentiates the Sensitivity to MDM2 Inhibitors in a p53-Dependent Manner. Mol. Cancer Ther. 2016, 15, 379-391. [CrossRef] [PubMed]

24. Sriraman, A.; Radovanović, M.; Wienken, M.; Najafova, Z.; Li, Y.; Dobbelstein, M. Cooperation of Nutlin-3a and a Wip1 inhibitor to induce p53 activity. Oncotarget 2016, 7, 31623-31638. [CrossRef]

25. Wu, C.-E.; Esfandiari, A.; Ho, Y.-H.; Wang, N.; Mahdi, A.; Aptullahoglu, E.; Lovat, P.; Lunec, J. Targeting negative regulation of p53 by MDM2 and WIP1 as a therapeutic strategy in cutaneous melanoma. Br. J. Cancer 2017, 118, 495-508. [CrossRef]

26. Hanahan, D.; Weinberg, R.A. Hallmarks of Cancer: The Next Generation. Cell 2011, 144, 646-674. [CrossRef]

27. Tsujimoto, Y.; Cossman, J.; Jaffe, E.; Croce, C.M. Involvement of the bcl-2 Gene in Human Follicular Lymphoma. Science 1985, 228, 1440-1443. [CrossRef] [PubMed]

28. Delia, D.; Aiello, A.; Soligo, D.; Fontanella, E.; Melani, C.; Pezzella, F.; Pierotti, M.A.; Della Porta, G. bcl-2 proto-oncogene expression in normal and neoplastic human myeloid cells. Blood 1992, 79, 1291-1298. [CrossRef] [PubMed]

29. Aisenberg, A.C.; Wilkes, B.M.; Jacobson, J.O. The bcl-2 gene is rearranged in many diffuse B-cell lymphomas. Blood 1988, 71, 969-972. [CrossRef]

30. Beroukhim, R.; Mermel, C.H.; Porter, D.; Wei, G.; Raychaudhuri, S.; Donovan, J.; Barretina, J.; Boehm, J.S.; Dobson, J.; Urashima, M.; et al. The landscape of somatic copy-number alteration across human cancers. Nature 2010, 463, 899-905. [CrossRef]

31. Hoffman-Luca, C.G.; Ziazadeh, D.; McEachern, N.; Zhao, Y.; Sun, W.; Debussche, L.; Wang, S. Elucidation of Acquired Resistance to Bcl-2 and MDM2 Inhibitors in Acute Leukemia In Vitro and In Vivo. Clin. Cancer Res. 2015, 21, 2558-2568. [CrossRef]

32. Carter, B.Z.; Mak, P.Y.; Mak, D.H.; Ruvolo, V.R.; Schober, W.; McQueen, T.; Cortes, J.; Kantarjian, H.M.; Champlin, R.E.; Konopleva, M.; et al. Synergistic effects of p53 activation via MDM2 inhibition in combination with inhibition of Bcl-2 or Bcr-Abl in CD34+ proliferating and quiescent chronic myeloid leukemia blast crisis cells. Oncotarget 2015, 6, 30487-30499. [CrossRef]

33. Pan, R.; Ruvolo, V.; Mu, H.; Leverson, J.D.; Nichols, G.; Reed, J.C.; Konopleva, M.; Andreeff, M. Synthetic Lethality of Combined Bcl-2 Inhibition and p53 Activation in AML: Mechanisms and Superior Antileukemic Efficacy. Cancer Cell 2017, 32, 748-760. [CrossRef] [PubMed]

34. Decaudin, D.; Leitz, E.F.D.; Nemati, F.; Tarin, M.; Naguez, A.; Zerara, M.; Marande, B.; Vivet-Noguer, R.; Halilovic, E.; Fabre, C.; et al. Preclinical evaluation of drug combinations identifies co-inhibition of Bcl-2/XL/W and MDM2 as a potential therapy in uveal melanoma. Eur. J. Cancer 2020, 126, 93-103. [CrossRef]

35. Mallick, D.; Soderquist, R.S.; Bates, D.; Eastman, A. Confounding off-target effects of BH3 mimetics at commonly used concentrations: MIM1, UMI-77, and A-1210477. Cell Death Dis. 2019, 10, 185. [CrossRef] [PubMed]

36. Cohen, N.A.; Stewart, M.L.; Gavathiotis, E.; Tepper, J.L.; Bruekner, S.R.; Koss, B.; Opferman, J.T.; Walensky, L.D. A Competitive Stapled Peptide Screen Identifies a Selective Small Molecule that Overcomes MCL-1-Dependent Leukemia Cell Survival. Chem. Biol. 2012, 19, 1175-1186. [CrossRef]

37. Respondek, M.; Beberok, A.; Rok, J.; Rzepka, Z.; Wrześniok, D.; Buszman, E. MIM1, the Mcl-1—specific BH3 mimetic induces apoptosis in human U87MG glioblastoma cells. Toxicol. In Vitro 2018, 53, 126-135. [CrossRef] [PubMed]

38. Respondek, M.; Beberok, A.; Rzepka, Z.; Rok, J.; Wrześniok, D. MIM1 induces COLO829 melanoma cell death through mitochondrial membrane breakdown, GSH depletion, and DNA damage. Fundam. Clin. Pharmacol. 2019, 34, 20-31. [CrossRef] [PubMed]

39. Ianevski, A.; He, L.; Aittokallio, T.; Tang, J. SynergyFinder: A web application for analyzing drug combination dose-response matrix data. Bioinformatics 2017, 33, 2413-2415. [CrossRef]

40. Italiano, A.; Miller, W.H.; Blay, J.-Y.; Gietema, J.A.; Bang, Y.-J.; Mileshkin, L.R.; Hirte, H.W.; Higgins, B.; Blotner, S.; Nichols, G.L.; et al. Phase I study of daily and weekly regimens of the orally administered MDM2 antagonist idasanutlin in patients with advanced tumors. Investig. New Drugs 2021, 39, 1587-1597. [CrossRef]

41. Zanjirband, M.; Edmondson, R.; Lunec, J. Pre-clinical efficacy and synergistic potential of the MDM2-p53 antagonists, Nutlin-3 and RG7388, as single agents and in combined treatment with cisplatin in ovarian cancer. Oncotarget 2016, 7, 40115-40134. [CrossRef] [PubMed] 
42. El-Deiry, W.S.; Tokino, T.; Velculescu, V.E.; Levy, D.B.; Parsons, R.; Trent, J.M.; Lin, D.; Mercer, W.E.; Kinzler, K.W.; Vogelstein, B. WAF1, a potential mediator of p53 tumor suppression. Cell 1993, 75, 817-825. [CrossRef]

43. Khoo, K.H.; Verma, C.S.; Lane, D.P. Drugging the p53 pathway: Understanding the route to clinical efficacy. Nat. Rev. Drug Discov. 2014, 13, 217-236. [CrossRef] [PubMed]

44. Kracikova, M.; Akiri, G.; George, A.; Sachidanandam, R.; Aaronson, S.A. A threshold mechanism mediates p53 cell fate decision between growth arrest and apoptosis. Cell Death Differ. 2013, 20, 576-588. [CrossRef]

45. Lu, M.; Breyssens, H.; Salter, V.; Zhong, S.; Hu, Y.; Baer, C.; Ratnayaka, I.; Sullivan, A.; Brown, N.R.; Endicott, J.; et al. Restoring p53 function in human melanoma cells by inhibiting MDM2 and cyclin B1/CDK1-phosphorylated nuclear iASPP. Cancer Cell 2013, 23, 618-633. [CrossRef]

46. Ciardullo, C.; Aptullahoglu, E.; Woodhouse, L.; Lin, W.-Y.; Wallis, J.P.; Marr, H.; Marshall, S.; Bown, N.; Willmore, E.; Lunec, J. Non-genotoxic MDM2 inhibition selectively induces a pro-apoptotic p53 gene signature in chronic lymphocytic leukemia cells. Haematologica 2019, 104, 2429-2442. [CrossRef]

47. Tracz-Gaszewska, Z.; Klimczak, M.; Biecek, P.; Herok, M.; Kosinski, M.; Olszewski, M.; Czerwińska, P.; Wiech, M.; Wiznerowicz, M.; Zylicz, A.; et al. Molecular chaperones in the acquisition of cancer cell chemoresistance with mutated TP53 and MDM2 up-regulation. Oncotarget 2017, 8, 82123-82143. [CrossRef]

48. Maganti, H.B.; Jrade, H.; Cafariello, C.; Rothberg, J.L.M.; Porter, C.J.; Yockell-Lelièvre, J.; Battaion, H.L.; Khan, S.T.; Howard, J.P.; Li, Y.; et al. Targeting the MTF2-MDM2 Axis Sensitizes Refractory Acute Myeloid Leukemia to Chemotherapy. Cancer Discov. 2018, 8, 1376-1389. [CrossRef]

49. Wang, W.; Hu, B.; Qin, J.; Cheng, J.-W.; Li, X.; Rajaei, M.; Fan, J.; Yang, X.-R.; Zhang, R. A novel inhibitor of MDM2 oncogene blocks metastasis of hepatocellular carcinoma and overcomes chemoresistance. Genes Dis. 2019, 6, 419-430. [CrossRef]

50. Giordana, M.T.; Duó, D.; Gasverde, S.; Trevisan, E.; Boghi, A.; Morra, I.; Pradotto, L.; Mauro, A.; Chió, A. MDM2 overexpression is associated with short survival in adults with medulloblastoma. Neuro Oncol. 2002, 4, 115-122. [CrossRef]

51. Gu, L.; Zhu, N.; Findley, H.W.; Zhou, M. MDM2 antagonist nutlin-3 is a potent inducer of apoptosis in pediatric acute lymphoblastic leukemia cells with wild-type p53 and overexpression of MDM2. Leukemia 2008, 22, 730-739. [CrossRef]

52. Zhang, X.; Gu, L.; Li, J.; Shah, N.; He, J.; Yang, L.; Hu, Q.; Zhou, M. Degradation of MDM2 by the Interaction between Berberine and DAXX Leads to Potent Apoptosis in MDM2-Overexpressing Cancer Cells. Cancer Res. 2010, 70, 9895-9904. [CrossRef] [PubMed]

53. Barretina, J.; Taylor, B.S.; Banerji, S.; Ramos, A.H.; Lagos-Quintana, M.; DeCarolis, P.L.; Shah, K.; Socci, N.D.; Weir, B.A.; Ho, A.; et al. Subtype-specific genomic alterations define new targets for soft-tissue sarcoma therapy. Nat. Genet. 2010, 42, 715-721. [CrossRef]

54. Hensley, M.L.; Chavan, S.S.; Solit, D.B.; Murali, R.; Soslow, R.; Chiang, S.; Jungbluth, A.A.; Bandlamudi, C.; Srinivasan, P.; Tap, W.D.; et al. Genomic Landscape of Uterine Sarcomas Defined Through Prospective Clinical Sequencing. Clin. Cancer Res. 2020, 26, 3881-3888. [CrossRef] [PubMed]

55. Wu, C.-E.; Huang, C.-Y.; Chen, C.-P.; Pan, Y.-R.; Chang, J.; Chen, J.-S.; Yeh, C.-N.; Lunec, J. WIP1 Inhibition by GSK2830371 Potentiates HDM201 through Enhanced p53 Phosphorylation and Activation in Liver Adenocarcinoma Cells. Cancers 2021, 13, 3876. [CrossRef] [PubMed]

56. Mukherjee, N.; Amato, C.M.; Skees, J.; Todd, K.J.; Lambert, K.A.; Robinson, W.A.; Van Gulick, R.; Weight, R.M.; Dart, C.R.; Tobin, R.P.; et al. Simultaneously Inhibiting BCL2 and MCL1 Is a Therapeutic Option for Patients with Advanced Melanoma. Cancers 2020, 12, 2182. [CrossRef]

57. Seiller, C.; Maiga, S.; Touzeau, C.; Bellanger, C.; Kervoëlen, C.; Descamps, G.; Maillet, L.; Moreau, P.; Deceunynck, C.; Bougie, P.G.; et al. Dual targeting of BCL2 and MCL1 rescues myeloma cells resistant to BCL2 and MCL1 inhibitors associated with the formation of BAX/BAK hetero-complexes. Cell Death Dis. 2020, 11, 1-14. [CrossRef]

58. Jeay, S.; Gaulis, S.; Ferretti, S.; Bitter, H.; Ito, M.; Valat, T.; Murakami, M.; Ruetz, S.; Guthy, D.A.; Rynn, C. A distinct p53 target gene set predicts for response to the selective p53-HDM2 inhibitor NVP-CGM097. Elife 2015, 4, e06498. [CrossRef] [PubMed]

59. Sonkin, D. Expression signature based on TP53 target genes doesn't predict response to TP53-MDM2 inhibitor in wild type TP53 tumors. ELife 2015, 4, e10279. [CrossRef] 